\title{
Stratospheric aerosol extinction profiles from SCIAMACHY solar occultation
}

\author{
Stefan Noël ${ }^{1}$, Klaus Bramstedt ${ }^{1}$, Alexei Rozanov ${ }^{1}$, Elizaveta Malinina ${ }^{1, a}$, Heinrich Bovensmann ${ }^{1}$, and \\ John P. Burrows ${ }^{1}$ \\ ${ }^{1}$ Institute of Environmental Physics, University of Bremen, FB 1, P.O. Box 330440, 28334 Bremen, Germany \\ a now at: the Canadian Centre for Climate Modelling and Analysis (CCCma), \\ Environment and Climate Change Canada, Victoria, Canada
}

Correspondence: Stefan Noël (stefan.noel@iup.physik.uni-bremen.de)

Received: 30 March 2020 - Discussion started: 12 May 2020

Revised: 25 August 2020 - Accepted: 28 August 2020 - Published: 22 October 2020

\begin{abstract}
The Scanning Imaging Absorption spectroMeter for Atmospheric CHartographY (SCIAMACHY) instrument on Envisat provided, between August 2002 and April 2012, measurements of solar and Earthshine spectra from the UV to the shortwave infrared spectral region in multiple viewing geometries.
\end{abstract}

We present a new approach to derive stratospheric aerosol extinction profiles from SCIAMACHY solar occultation measurements based on an onion-peeling method similar to the onion-peeling differential optical absorption spectroscopy (DOAS) retrieval, which has already been successfully used for the derivation of greenhouse gas profiles. Since the retrieval of aerosol extinction requires as input measured transmissions in absolute units, an improved radiometric calibration of the SCIAMACHY solar occultation measurements has been developed, which considers various instrumental and atmospheric effects specific to solar occultation.

The aerosol extinction retrieval can in principle be applied to all wavelengths measured by SCIAMACHY. As a first application, we show results for 452,525 and $750 \mathrm{~nm}$. The SCIAMACHY solar occultation time series has been processed, covering a latitudinal range of about $50-70^{\circ} \mathrm{N}$. Reasonable aerosol extinctions are derived between about 15 and $30 \mathrm{~km}$ with typically larger uncertainties at higher altitudes due to decreasing aerosol extinction.

Comparisons with collocated Stratospheric Aerosol and Gas Experiment II (SAGE-II) and SCIAMACHY limb aerosol data products revealed good agreement with essentially no mean bias. However, dependent on altitude, differ- ences of up to $\pm 20 \%-30 \%$ to SAGE-II at 452 and $525 \mathrm{~nm}$ are observed. Similar results are obtained from comparisons with SAGE-III.

SCIAMACHY solar occultation data at $750 \mathrm{~nm}$ have been compared with corresponding SAGE-III, Optical Spectrograph and InfraRed Imager System (OSIRIS) and SCIAMACHY limb results. The agreement with SCIAMACHY limb data at $750 \mathrm{~nm}$ is within 5\%-20\% between 17 and $27 \mathrm{~km}$. SAGE-III and OSIRIS show at this wavelength and altitude range on average about $40 \%$ and $25 \%$ smaller values, with some additional $10 \%-20 \%$ modulation with altitude.

The altitude variations in the differences are mainly caused by systematic vertical oscillations in the SCIAMACHY occultation data of up to $30 \%$ below about $25 \mathrm{~km}$. These oscillations decrease to amplitudes below $10 \%$ with increasing number of collocations and are no longer visible in monthly anomalies.

Major volcanic eruptions as well as occurrences of polar stratospheric clouds (PSCs) can be identified in the time series of aerosol extinction data and related anomalies. The influence of the quasi-biennial oscillation $(\mathrm{QBO})$ is visible above $25 \mathrm{~km}$.

\section{Introduction}

Stratospheric aerosols play an important role in climate as they affect radiative forcing either by scattering and absorption of light (direct effect) or by their impact on clouds and 
ozone (indirect effect). Especially, aerosols affect the creation of polar stratospheric clouds (PSCs) on which surface $\mathrm{O}_{3}$ depletion takes place.

The main constituents of stratospheric aerosols are sulfuric acid $\left(\mathrm{H}_{2} \mathrm{SO}_{4}\right)$ and (liquid) water $\left(\mathrm{H}_{2} \mathrm{O}\right)$. Sulfuric acid is mostly produced from oxidation of carbonyl sulfide (OCS) and sulfur dioxide $\left(\mathrm{SO}_{2}\right)$. OCS has mostly marine origin, while $\mathrm{SO}_{2}$ mainly originates from volcanic eruptions, biomass burning (both natural and anthropogenic origin) and fossil fuel combustion. The main transport path of OCS and $\mathrm{SO}_{2}$ in the stratosphere during volcanic quiescent periods is the tropical upwelling. In addition, anthropogenic $\mathrm{SO}_{2}$ from fossil fuel combustion is transported to the stratosphere via the Asian monsoon (Randel et al., 2010), while pyrocumulus events represent a transport mechanism for biomass burning products. Large amounts of $\mathrm{SO}_{2}$ can be directly injected into the stratosphere by strong volcanic eruptions.

Information about stratospheric aerosols can be derived, e.g. from ground-based lidars or in situ balloon and aircraft measurements. However, these usually have a limited spatial and temporal coverage. Global measurements of stratospheric aerosols are only possible with satellite-based instruments; see Table 1.

These started in the 1970s with the suite of SAM (Stratospheric Aerosol Measurement) and SAGE (Stratospheric Aerosol and Gas Experiment) instruments (see, e.g. Chu and McCormick, 1979; Kent and McCormick, 1984; McCormick, 1987; Osborn et al., 1989; Russell and McCormick, 1989; Thomason and Taha, 2003; Thomason et al., 2008).

From 1991 to 2001, HALOE (Halogen Occultation Experiment on the Upper Atmosphere Research Satellite (UARS); see, e.g. Russell III et al., 1993; Lee et al., 2001) performed occultation measurements from which, among other atmospheric constituents, aerosol extinctions were also derived. Aerosol extinction profiles were also provided by the Polar Ozone and Aerosol Measurement (POAM) II and III between 1993 and 2005 (see, e.g. Bevilacqua et al., 1995; Randall et al., 1996, 2001). These were accompanied between 2002 and 2012 by the Envisat instruments: GOMOS (Global Ozone Monitoring by Occultation of Stars; Kyrölä et al., 2010), MIPAS (Michelson Interferometer for Passive Atmospheric Sounding; Fischer et al., 2008) and SCIAMACHY (Scanning Imaging Absorption Spectrometer for atMospheric CHartographY; see, e.g. Gottwald and Bovensmann, 2011). Currently, OSIRIS (Optical Spectrograph and InfraRed Imager System; see, e.g. Llewellyn et al., 2004; Bourassa et al., 2012; Rieger et al., 2014, 2019), ACE-MAESTRO (the Atmospheric Chemistry Experiment Measurement of Aerosol Extinction in the Stratosphere and Troposphere Retrieved by Occultation instrument; McElroy et al., 2007; Sioris et al., 2010), CALIOP (Cloud-Aerosol Lidar with Orthogonal Polarization; Winker et al., 2007; Vernier et al., 2011), OMPS (Ozone Mapping Profiler Suite; Jaross et al., 2014; Loughman et al., 2018; Chen et al.,
2018) and SAGE-III (from ISS; Cisewski et al., 2014) are still operational and deliver data on stratospheric aerosols. Note that the CALIOP instrument is an active sounder, which is primarily intended for tropospheric aerosol extinction measurements. However, recently also results from stratospheric aerosol extinction retrievals have become available; see Thomason et al. (2007), Pitts et al. (2018) and Kar et al. (2019).

These satellite instruments measure via different viewing geometries, all having advantages and drawbacks. Occultation instruments can more or less directly measure aerosol extinction (i.e. the sum of scattering and absorption of light). Limb data are usually more difficult to be analysed; see, e.g. Malinina et al. (2018), who derived particle size distributions from SCIAMACHY limb measurements.

In the following, we describe a new method to derive stratospheric aerosol extinction profiles from SCIAMACHY solar occultation data. This method is in principle able to derive aerosol extinction profiles at any wavelength measured by SCIAMACHY. To demonstrate this, we concentrate in the current study on selected wavelengths in the visible/near-infrared spectral region where also suitable correlative data sets (SAGE-II and SCIAMACHY limb) are available, namely 452,525 and $750 \mathrm{~nm}$.

The paper is organised as follows: Sect. 2 lists the input data used in this study. In Sect. 3, the SCIAMACHY occultation data are described with the focus on the newly developed radiometric calibration, which is the largest challenge in this context. Section 4 explains the aerosol extinction retrieval method. The corresponding retrieval results and their first validation are then shown in Sect. 5. In Sect. 6, we show time series of the aerosol extinction data. The conclusions are summarised in Sect. 7. Some details on the methods used in this study are given in the Appendix.

\section{Used data}

\subsection{SCIAMACHY spectra}

The SCIAMACHY solar occultation data used in this study were extracted from the SCIAMACHY level 1 version 8 product with all calibrations applied except for polarisation correction as solar irradiances are unpolarised. Additional pointing corrections as described in Bramstedt et al. (2017) have been applied such that the tangent height knowledge is better than $26 \mathrm{~m}$. These radiance measurements are then converted into transmissions using additional corrections as will be described in detail in Sect. 3 .

\subsection{ECMWF ERA-Interim}

ECMWF ERA-Interim model data (Dee et al., 2011) are used in the retrieval to account for pressure and temperature profiles at the time and location of the measurements (see 
Table 1. Satellite measurements of stratospheric aerosols.

\begin{tabular}{lllll}
\hline Instrument & Platform & $\begin{array}{l}\text { Measurement } \\
\text { time }\end{array}$ & Viewing geometry & Latitude range \\
\hline SAM & Apollo-Soyuz & 1975 & solar occultation & proof-of-concept mission \\
SAM-II & Nimbus-7 & $1978-1993$ & $\begin{array}{l}\text { solar occultation } \\
\text { solar occultation }\end{array}$ & $64-80^{\circ} \mathrm{S} ; 64-80^{\circ} \mathrm{N}$ \\
SAGE-I & AEM-B & $1979-1981$ & $72^{\circ} \mathrm{S}-72^{\circ} \mathrm{N}$ \\
SAGE-II & ERBS & $1984-2005$ & solar occultation & $80^{\circ} \mathrm{S}-80^{\circ} \mathrm{N}$ \\
SAGE-III & Meteor-3M & $2001-2006$ & solar and lunar occultation & $30-50^{\circ} \mathrm{S} ; 50-80^{\circ} \mathrm{N}$ \\
\hline HALOE & UARS & $1991-2001$ & solar occultation & $80^{\circ} \mathrm{S}-80^{\circ} \mathrm{N}$ \\
POAM-II & SPOT-3 & $1993-1996$ & solar occultation & $63-88^{\circ} \mathrm{S} ; 55-71^{\circ} \mathrm{N}$ \\
POAM-III & SPOT-4 & $1998-2005$ & solar occultation & $63-88^{\circ} \mathrm{S} ; 55-71^{\circ} \mathrm{N}$ \\
\hline GOMOS & Envisat & $2002-2012$ & stellar occultation & global \\
MIPAS & Envisat & $2002-2012$ & limb & global \\
SCIAMACHY & Envisat & $2002-2012$ & nadir*, limb, solar and lunar* occultation $^{\circ}$ & glimb; 49-69 $\mathrm{N}$ (solar occ.) \\
\hline OSIRIS & Odin & since 2001 & limb & global \\
ACE-MAESTRO & SCISAT & since 2003 & solar occultation & $82^{\circ} \mathrm{S}-82^{\circ} \mathrm{N}$ \\
CALIOP & CALIPSO & since 2006 & nadir & global \\
OMPS & Suomi NPP & since 2011 & nadir* and limb & $60^{\circ} \mathrm{S}-60^{\circ} \mathrm{N}$ \\
SAGE-III & ISS & since 2017 & solar occultation & \\
\hline
\end{tabular}

* No stratospheric aerosol data.

Sect. 4.1). These data are available every $6 \mathrm{~h}$ on a $0.75^{\circ}$ horizontal grid and on 60 altitude levels.

\subsection{SAGE-II profiles}

The SAGE-II instrument performed solar occultation measurements from 1984 to 2005 and provided aerosol extinction profiles at several wavelengths $(386,452,525,1020 \mathrm{~nm})$ as well as profiles of $\mathrm{O}_{3}, \mathrm{NO}_{2}$ and $\mathrm{H}_{2} \mathrm{O}$. In this study, we use SAGE-II v7.00A sunset aerosol extinction data (Damadeo et al., 2013) from the overlap period with SCIAMACHY (2002 to 2005) at 452 and $525 \mathrm{~nm}$ for comparisons. We selected collocated data within a maximum spatial distance of $800 \mathrm{~km}$. Since both data sets are based on sunset measurements, the actual time differences are always smaller than $1 \mathrm{~h}$. These criteria result in 700 collocations.

\subsection{SAGE-III profiles}

The SAGE-III instrument flown on Meteor-3M provided between 2002 and 2005 aerosol extinction profiles from solar occultation measurements at nine wavelengths from 384.3 to $1545.2 \mathrm{~nm}$. Here, we use SAGE-III v4.0 sunset aerosol extinction data (Thomason and Taha, 2003) from the overlap period with SCIAMACHY (2002 to 2005) at 449, 520 and $755 \mathrm{~nm}$. As for SAGE-III, we took collocated data within $800 \mathrm{~km}$ distance. The maximum time offset is below $1 \mathrm{~h}$. The number of achieved collocations is 5505 .

\subsection{OSIRIS limb aerosol}

The OSIRIS instrument on Odin provides limb aerosol extinctions at $750 \mathrm{~nm}$ since 2001; see Rieger et al. (2014). For the comparisons with SCIAMACHY solar occultation data, we use product v7.0 (Rieger et al., 2019) and collocations with a maximum spatial/time difference of $800 \mathrm{~km} / 9 \mathrm{~h}$. There are 12108 collocations but essentially no collocations between November and February. Relaxation of the collocation criteria, e.g. to $1000 \mathrm{~km} / 12 \mathrm{~h}$, does not help here. This is because OSIRIS observation geometry and orbit parameters result in measurement gaps at winter high latitudes.

\subsection{SCIAMACHY limb aerosol}

The SCIAMACHY limb aerosol extinction product v1.4 was obtained by using the algorithm described in Rieger et al. (2018). It comprises stratospheric profiles derived from SCIAMACHY limb measurements at $750 \mathrm{~nm}$. The data have been filtered according to the recommendations given by the data providers in the accompanying README file; especially, invalid data and data points with a vertical resolution larger than $7 \mathrm{~km}$ or aerosol extinctions exceeding $0.1 \mathrm{~km}^{-1}$ have not been used. The spatial collocation criterion is the same as for SAGE-II, but we used a maximum time difference of $10 \mathrm{~h}$. This is necessary to also achieve collocations in summer. 


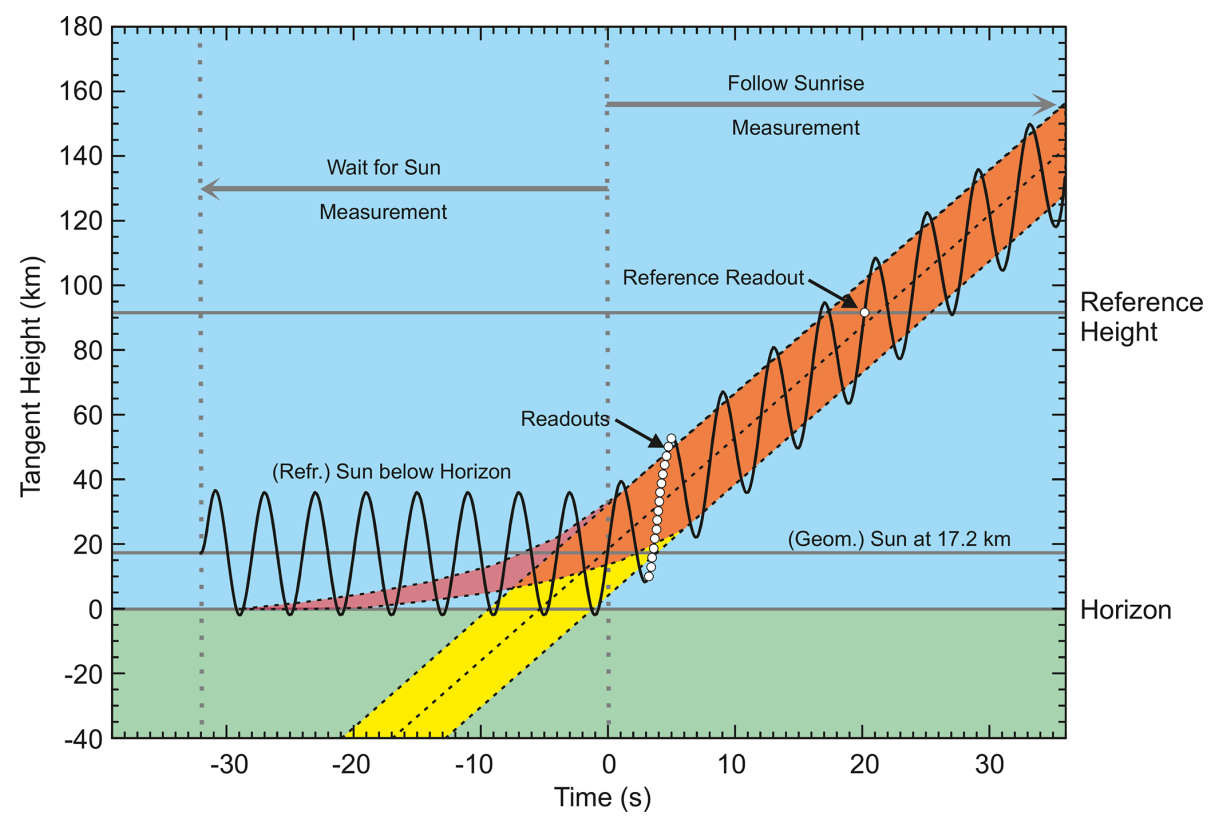

Figure 1. SCIAMACHY solar occultation measurement (figure from Noël et al., 2016).

\section{SCIAMACHY occultation}

\subsection{Measurements}

The SCIAMACHY instrument performed measurements in nadir, limb and solar and lunar occultation geometry covering continuously the spectral range from about 214 to $1750 \mathrm{~nm}$ and two additional bands at around 2000 and $2400 \mathrm{~nm}$.

SCIAMACHY performed solar occultation measurements in every orbit in the Northern Hemisphere (between about 50 and $70^{\circ} \mathrm{N}$ ) during time of (local) sunset. During such a measurement, SCIAMACHY observed the (apparently) rising Sun through the atmosphere with the following typical measurement sequence (see also Fig. 1, from Noël et al., 2016):

1. perform a sequence of up- and downward scans around an altitude of $17.2 \mathrm{~km}$ until the centre of the (unrefracted) Sun reaches this altitude;

2. switch on the so-called Sun follower in azimuthal direction to horizontally align the viewing direction to the intensity centre of the Sun; and

3. follow the rising Sun while scanning vertically around the (predicted) centre of the Sun until about a tangent altitude of $100 \mathrm{~km}$.

Above $100 \mathrm{~km}$, either special solar calibration measurements are performed or the scan over the Sun is continued up to about $250 \mathrm{~km}$. In this study, we concentrate on data below $100 \mathrm{~km}$, such that all available solar occultation measurements can be used.

\subsection{Transmissions}

The aerosol extinction retrieval (see below) requires as input atmospheric transmissions. In order to derive these transmissions, the individual SCIAMACHY spectra are in a first step normalised to a reference spectrum obtained at a high tangent altitude of about $90 \mathrm{~km}$.

This is done independently for up- and downward scans. With this, all possibly erroneous multiplicative calibration factors (e.g. most degradation effects or systematic errors in radiometric calibration) cancel out, which is why occultation measurements are sometimes called "self-calibrating".

However, this is not really the case for SCIAMACHY because of the scan over the Sun. The width of the instantaneous field of view (IFOV) of SCIAMACHY is in solar occultation mode about $0.7^{\circ}$; the height is about $0.045^{\circ}$. As the diameter of the Sun is about $0.5^{\circ}$, this implies a strongly varying signal over the scan as different parts of the Sun are seen at each readout. Furthermore, refraction effects and additional problems due to, e.g. mispointing and jumps in the signal when switching on the Sun follower need to be taken into account. This is explained in the following subsections.

\subsubsection{Radiometric calibration/scan correction}

The largest impact on the measured signal is related to the area of the Sun seen during each readout, which varies over the scan. This is mainly a geometric effect, which is illustrated in Fig. 2. Depending on the vertical position of the SCIAMACHY IFOV relative to the centre of the Sun, different areas of the IFOV are illuminated. The measured signal 
then varies approximately with the size of the illuminated area.

Figure $3 b$ and $d$ show this varying signal for the reference scan at high tangent altitudes, where atmospheric absorption and refraction are small and can be neglected. All data are normalised to the (interpolated) maximum signal of the scan. In Fig. 3b, the signal is shown for an upward and a downward scan as function of geometric tangent altitude. Because the Sun is (relative to the instrument) rising during the measurement, an upward scan covers a larger altitude range than a downward scan. However, as can be seen in Fig. 3d, the variation of the signal becomes very similar when plotted as function of angular (vertical) distance from the centre of the Sun. The thick black line in this figure shows the result of a simple geometrical model of the varying area when assuming a circular Sun disc of diameter $0.26^{\circ}$ with homogeneous brightness. The overall shape of the measurements is reproduced quite well by the black line; the deviations are caused by the fact that (1) the real Sun does not have the same brightness everywhere (mainly because of limb darkening effects), and (2) the measured signal is an integral over the IFOV in the vertical direction $\left(0.045^{\circ}\right.$ corresponding to about $\left.2.6 \mathrm{~km}\right)$ which smears out the black curve along the $x$ axis.

Figure $3 \mathrm{a}$ and $\mathrm{c}$ show the corresponding measured transmissions for various scans at lower tangent altitudes as function of tangent height (Fig. 3a) and distance to the Sun centre (Fig. 3c). The normalisation is the same as for the right plots; i.e. all upward/downward scans (even/odd numbers) are normalised to the maximum value of the reference measurement (green/red curves in the right plots). Due to increased atmospheric absorption and scattering, the transmissions decrease at lower altitudes. In addition, as can be seen in Fig. 3b, the maximum signal of the scan shifts to the right with decreasing altitude due to increasing refraction.

Figure 3 also shows that the measured signal for one scan is not symmetrical relative to the Sun centre; i.e. the signal drops to zero only on one side. This is because the position and elevation rate of the Sun assumed in the commanding of the measurement were derived from predicted orbital information. This results in a scan which is not exactly centred on the (true) Sun. This may also lead to azimuthal offsets (see Fig. 2b), which are corrected by use of the Sun follower (see above), but this can introduce jumps in the signal at altitudes around $17 \mathrm{~km}$ which require special treatment (see Appendix A).

To correct for the scan effect, we define a (numerical) Sun shape function $S$, which is the interpolated measured transmission $\left(T^{\mathrm{m}}\right)$ for a scan around a reference altitude of about $90 \mathrm{~km}$ as function of angular distance from the centre of the Sun $(\alpha)$, as shown in Fig. 3d. This is done for each measurement and independently for both up- and downscans in order to reduce possible systematic effects caused by the scan direction. Note that $S$ describes the shape of the Sun without atmospheric effects like refraction or influence of aerosol or clouds which can be neglected at $90 \mathrm{~km}$.
To account for refraction effects, we use a simple model similar to the one used in the SAGE-II project (Damadeo et al., 2013); see Fig. 4. It is assumed that refraction occurs only at the tangent point with the basic parameter being the bending angle $(\delta)$. This bending angle decreases with altitude and is essentially a function of pressure. In the stratosphere, the overall altitude variation of $\delta$ can therefore be described by an exponential function of tangent height $z$ :

$\delta=\exp (a+b z)$

The parameters $a$ and $b$ depend on atmospheric conditions (and also on wavelength) and are different for each measured profile. $b$ is typically negative, as refraction effects decrease with altitude. Therefore, we determine these parameters from the measurements (see Appendix B). From these, we then get for each measurement the bending angle $\delta$ from which we calculate the distance $\alpha$ of the observed point on the Sun to the Sun centre via

$\alpha=\gamma-\beta-\delta$

Here, $\gamma$ is the line-of-sight (LOS) zenith angle, and $\beta$ is the direction of the "true" Sun (i.e. without refraction). The latter is essentially the solar zenith angle (SZA) at the satellite position, i.e. $\beta=180^{\circ}-\mathrm{SZA}$. The LOS zenith angle $\gamma$ and the solar zenith angle are given in the SCIAMACHY level 1 product for the centre of the IFOV. As we assume a horizontally homogeneous atmosphere (within the range of one measured profile), azimuthal differences are not relevant in this context. However, as mentioned before, possible azimuthal jumps at lower altitudes need to be considered; see Appendix A.

The expected transmission corresponding to the distance $\alpha$ is then given by the Sun shape function $S(\alpha)$ derived from the reference scans (see above). The scan-corrected transmission $T$ as function of tangent altitude $z_{i}$ for readout $i$ of an occultation measurement is then derived from

$T_{i}=T\left(z_{i}\right)=T_{i}^{\mathrm{m}} / S\left(\alpha_{i}\right)$

\subsection{Selection of subset of readouts}

Prior to the retrieval (see Sect. 4.1), the measured transmissions need to be interpolated to a fixed altitude grid. Therefore, it is sufficient to use only a subset of the measured spectra for this. This subset is basically selected by using readouts with the highest (uncorrected) transmission signal, which corresponds, e.g. to the envelope of the data points shown in Fig. 3a. As an additional criterion, we only take data points with an altitude difference of $0.5 \mathrm{~km}$ or larger (when starting at the top and then going downwards in altitude). An example showing the results of this procedure is given in Sect. 5.1. 
(a) Ideal case

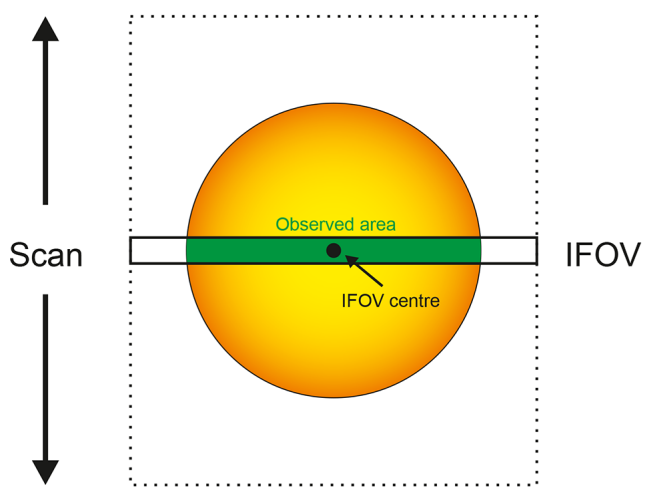

(b) With mispointing

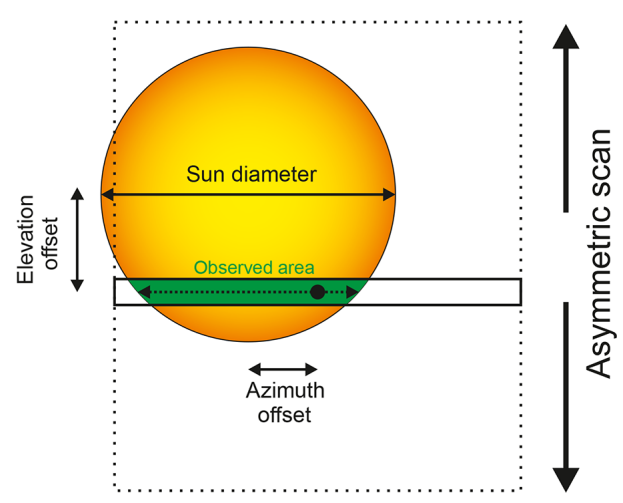

Figure 2. SCIAMACHY instantaneous field of view (IFOV) while scanning over the Sun. (a) Ideal case (Sun in centre of IFOV). (b) With mispointing (shift between centres of Sun and IFOV); this is actually the nominal case.
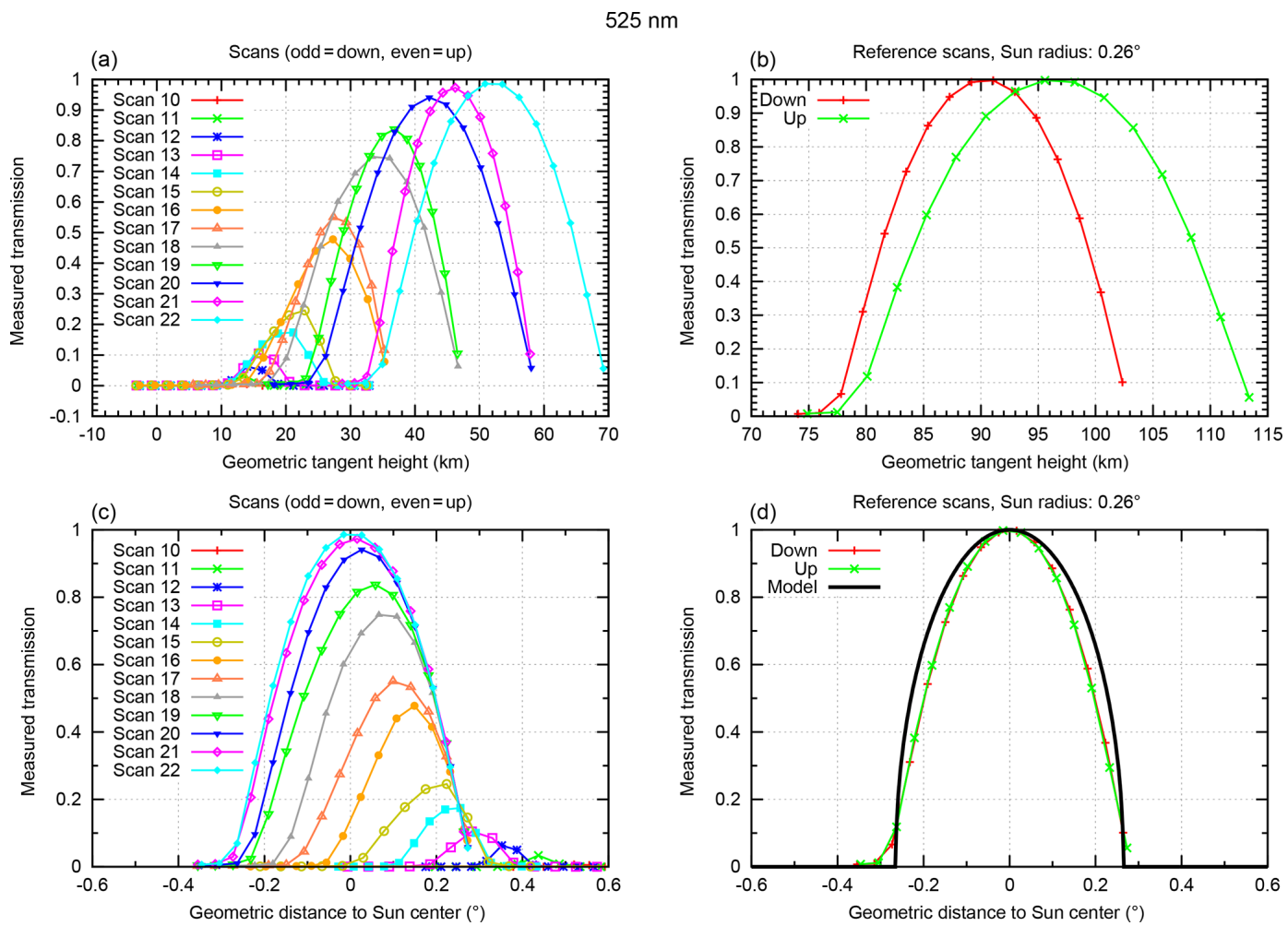

Figure 3. SCIAMACHY transmissions at $525 \mathrm{~nm}$. (a) Measured transmission as function of tangent altitude for different scans. (b) Reference transmissions as function of tangent altitude for up- and downscans. (c) Measured transmission as function of distance to Sun centre. (d) Transmissions as function of distance to Sun centre and corresponding model.

\section{Retrieval method}

The basic idea for the aerosol extinction retrieval is to use a two-step approach:

1. The first step is to apply the onion-peeling differential optical absorption spectroscopy (DOAS) retrieval method to correct the measured transmissions for Rayleigh scattering and gas absorptions.

2. The second step is to use an onion-peeling method to determine aerosol extinctions from corrected transmissions for different altitude layers, starting with the highest layer. 


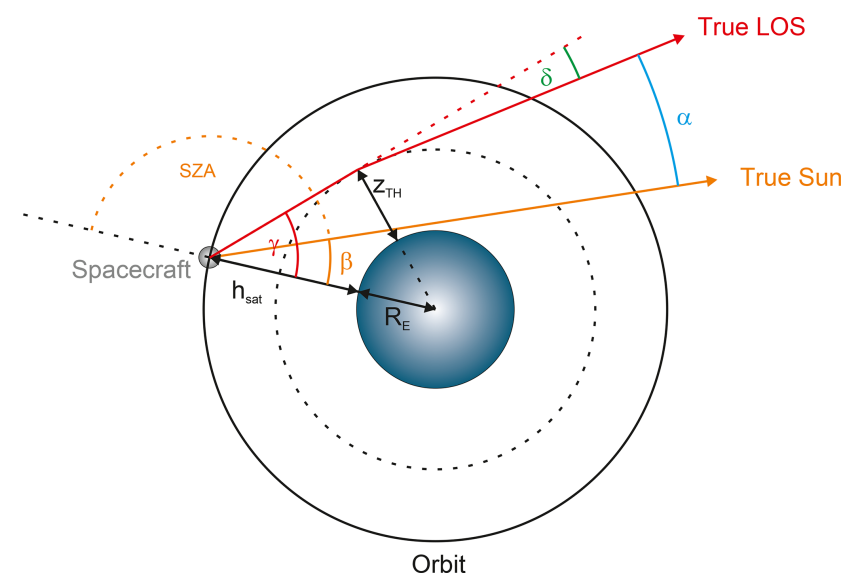

Figure 4. Definition of angles and other quantities used in the refraction model.

These two steps are described in more detail in the following subsections.

With this approach, it is possible to determine aerosol extinctions even at wavelengths where gases absorb light (since this absorption is fitted). In addition, the method also delivers profiles of the absorbing gases. However, these derived stratospheric gas profiles (in the present case for $\mathrm{O}_{3}$ and $\mathrm{NO}_{2}$ ) are not the primary focus of the current study, as retrieval settings are optimised for aerosol extinction.

\subsection{Onion-peeling DOAS approach}

The onion-peeling DOAS (ONPD) retrieval method has been originally developed to derive stratospheric profiles of greenhouse gases. So far, it has been applied to the retrieval of water vapour, $\mathrm{CO}_{2}$ and methane (Noël et al., 2010, 2011, 2016, 2018). The retrieval method is described in detail in these publications; we therefore give here only a basic summary and the specific settings used in the context of this study.

\subsubsection{Description of method}

In the ONPD approach, the atmosphere is divided into layers. All measured transmission spectra are interpolated to this grid. For each tangent height $j$, a weighting function DOAS fit (see, e.g. Coldewey-Egbers et al., 2005) is performed using the following formula:

$\ln T_{j}^{\text {interp }}=\ln T_{j, \text { ref }}+\sum_{k} \sum_{i} w_{i j, k} a_{i, k}+P_{j}$.

Here, $T_{j}^{\text {interp }}$ is the (interpolated) measured transmission for tangent height $j . T_{j \text {,ref }}$ is a reference transmission derived for the same viewing geometry from a radiative transfer model, in our case SCIATRAN v3.7 (Rozanov et al., 2013) in occultation mode. The index $i$ refers to the atmospheric layers, $k$ to the different absorbers considered in the fit. $w_{i j, k}$ is the relative weighting function, which is also derived by the radiative transfer model. It describes how the (logarithmic) transmission for tangent height $j$ changes if the amount of absorber $k$ is changed by $100 \%$ in layer $i . a_{i, k}$ is a scalar factor, which describes the actual change of absorber $k$ in layer $i$ relative to the assumptions in the radiative transfer model. Spectrally broadband absorption and scattering (especially due to aerosols) are described by a polynomial $P_{j}$.

The factors $a_{i, k}$ and the polynomial $P_{j}$ are fitted for each layer $j$, starting at the top layer and then propagating downwards. In each step, the results of the upper layers are taken into account. From the combination of the $a_{i, k}$ scaling factors with the a priori profiles assumed in the radiative transfer calculations, vertical profiles of the absorbers $k$ are derived. These profiles are then vertically smoothed using a boxcar of width $4.3 \mathrm{~km}$ to account for the vertical resolution of the measurements and to reduce vertical oscillations. The used width corresponds to the approximate vertical range covered during one readout (from combination of vertical size of the IFOV and the scan). This smoothing essentially also defines the vertical resolution of the resulting trace gas profiles. Reasonable results for greenhouse gases are achieved for altitudes between about 17 and $45 \mathrm{~km}$; see, e.g. Noël et al. (2018). At the wavelengths considered in the present study and with the improved calibration performed here, we expect that this validity range can be extended even to somewhat lower altitudes; see also below.

\subsubsection{Specific settings and sequence of fits}

The general ONPD settings are the same as described in Noël et al. (2018). We use a vertical layering from 0 to $50 \mathrm{~km}$ with $1 \mathrm{~km}$ steps. In general, the ONPD method uses a fixed database of reference transmissions derived with SCIATRAN assuming conditions of the 1976 US standard atmosphere (NASA, 1976). We correct for the actual conditions by using corresponding weighting functions via Eq. (4). For pressure and temperature, this is done by using as input data from the ECMWF ERA-Interim model. We select the profiles spatially and temporally closest to the measurements and interpolate them to the ONPD altitude grid.

In the current study, we have performed calculations for three different aerosol extinction wavelengths $\lambda_{\text {aer }}(452$, 525 and $750 \mathrm{~nm}$ ). The degree of the fitted polynomial is 2 in these cases. For consistency reasons and because the fitting windows are optimised for the aerosol extinction retrieval, we use a specific sequence of retrievals such that information obtained in one retrieval can be used in other retrievals. Therefore, we start with the retrieval for $\lambda_{\text {aer }}=525 \mathrm{~nm}$, from which we obtain $\mathrm{O}_{3}$ and $\mathrm{NO}_{2}$ profiles which are then used in the other retrievals. The detailed settings for each retrieval are summarised in Table 2. 
Table 2. Sequence and settings of ONPD retrieval.

\begin{tabular}{lcc|llll}
\hline Sequence no. & $\lambda_{\text {aer }}$ & Fit interval & & \multicolumn{4}{c}{ Considered absorbers (source/fit) } \\
\hline 1 & $525 \mathrm{~nm}$ & $510-580 \mathrm{~nm}$ & pressure (ECMWF) & temperature (ECMWF) & $\mathrm{O}_{3}($ fit $)$ & $\mathrm{NO}_{2}(\mathrm{fit})$ \\
2 & $452 \mathrm{~nm}$ & $440-460 \mathrm{~nm}$ & pressure (ECMWF) & temperature (ECMWF) & $\mathrm{O}_{3}(525 \mathrm{~nm})$ & $\mathrm{NO}_{2}(525 \mathrm{~nm})$ \\
3 & $750 \mathrm{~nm}$ & $750-758 \mathrm{~nm}$ & pressure (ECMWF) & temperature (ECMWF) & $\mathrm{O}_{3}(525 \mathrm{~nm})$ & \\
\hline
\end{tabular}

\subsection{Aerosol extinction retrieval}

The standard ONPD method does not require fully calibrated data as input because the fitted polynomials $P_{j}$ also account for possible multiplicative radiometric offsets, i.e. as caused by the scan over the Sun.

In the present study, we use fully calibrated transmissions as input. Therefore, the polynomials $P_{j}$ should essentially contain information about aerosol extinction in the atmosphere. This can be described by the following formula:

$P_{j}\left(\lambda_{\text {aer }}\right)=-\sum_{i} \epsilon_{i}\left(\lambda_{\text {aer }}\right) l_{i j}\left(\lambda_{\text {aer }}\right)$.

$P_{j}\left(\lambda_{\text {aer }}\right)$ is the value of the polynomial $P_{J}$ derived from the ONPD retrieval at the wavelength $\lambda_{\text {aer }}$, at which we want to determine the aerosol extinction. $l_{i j}$ is a (fixed) geometric factor which describes the length of the occultation light path in layer $i$ when looking at layer $j$. These path lengths are also derived from SCIATRAN for each atmospheric layer and viewing direction and consider refraction. They therefore also depend slightly on wavelength. $\epsilon_{i}$ is the aerosol extinction in layer $i$; this is the quantity we want to derive.

This is done - consistently with the ONPD approach - by using an onion-peeling method: we start at the top layer and then propagate downwards while taking into account the results from above. Contributions from below the current tangent $j$ (due to refraction and vertical size of the IFOV) are considered by assuming $\epsilon_{i}=\epsilon_{j}$ for $i<j$ when determining $\epsilon_{j}$. Since aerosol extinction typically increases with decreasing altitude, this results in a small overestimation but gives a stable solution.

\section{Results}

\subsection{Example on 11 September 2003}

To illustrate the outcome of the different calibration and retrieval parts described in the previous section, we present in this subsection as an example the results for orbit 8014 (on 11 September 2003). This orbit has been selected due to a collocation of SAGE-II and SCIAMACHY limb measurements, such that a direct comparison of aerosol extinction results is possible (see below).

Figure 5 shows the transmissions as function of altitude for the three selected aerosol extinction wavelengths. In the left column, the uncorrected transmissions (i.e. without scan correction) are shown in red (similar to the data shown in Fig. 3a). The black dots denote the selected subset of data which is used in the retrieval. Effects of the scan over the Sun are visible.

The right column of Fig. 5 shows the selected transmissions after the corrections explained above, which now smoothly decrease with altitude as it is expected. The variation of transmission with altitude is different for each wavelength due to different absorbing and scattering effects. In general, transmissions at shorter wavelengths are lower at lower altitudes mainly due to ozone absorption and stronger Rayleigh scattering. Below $10 \mathrm{~km}$, transmissions are close to zero due to the low input signal, which gives a lower limit for the later retrieval. At altitudes above about $30 \mathrm{~km}$, transmissions are close to 1 . Since aerosol extinction information is obtained from the difference of the transmission to 1 , this also implies an upper limit for the retrieval (see below).

The selected and corrected spectra are then fed into the ONPD retrieval (see Sect. 4.1), in which the background polynomial is fitted considering gas absorptions and Rayleigh scattering. The results of this retrieval for orbit 8014 are shown in Fig. 6. The left column of this figure shows the following (again for the different aerosol extinction wavelengths):

- the corrected measured logarithmic transmission at $25 \mathrm{~km}$ (thick grey line);

- the SCIATRAN reference model spectrum for US standard atmosphere conditions, including Rayleigh scattering (green line);

- the model spectrum corrected for actual temperature, pressure and absorption of gases as derived from the fit (blue line);

- the fitted background polynomial (pink line); and

- the fitted spectrum, i.e. the combination of the contributions of reference spectrum, absorption and polynomial (red line).

As the fit result (red) is very close to the measurement (grey), the right column of Fig. 6 shows the residual of both (measurement - fit), which is quite low (standard deviation below 0.002 ), indicating a good fit.

The white circles on the pink lines in Fig. 6 mark the value of the polynomial at the wavelength to be used for 
(a) $452 \mathrm{~nm}$ (uncorrected)

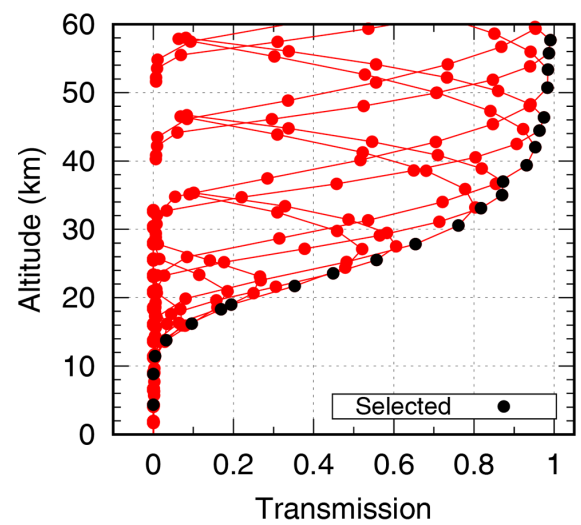

(c) $525 \mathrm{~nm}$ (uncorrected)

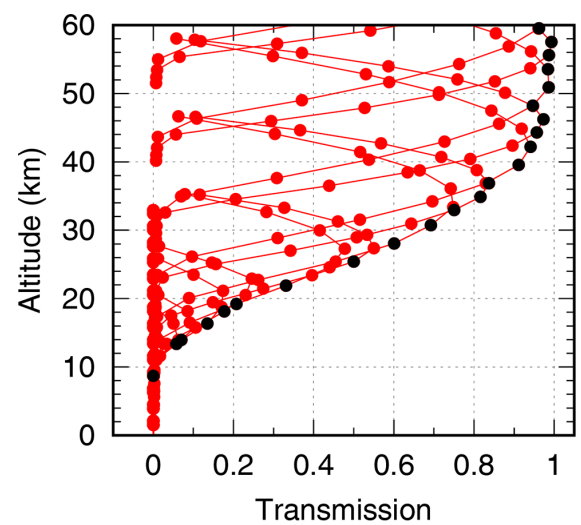

(e) $750 \mathrm{~nm}$ (uncorrected)

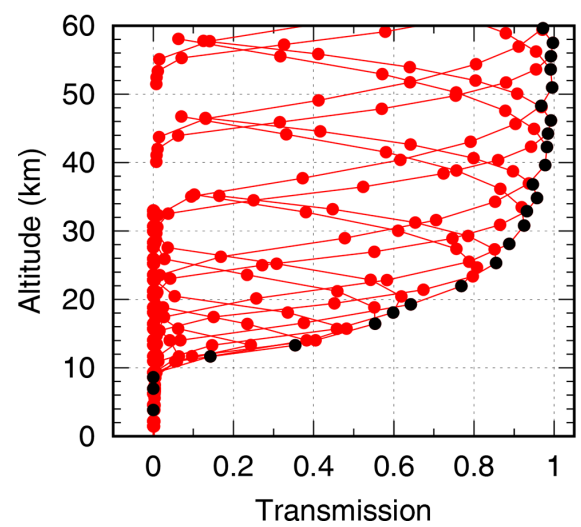

(b) $452 \mathrm{~nm}$ (corrected and selected)

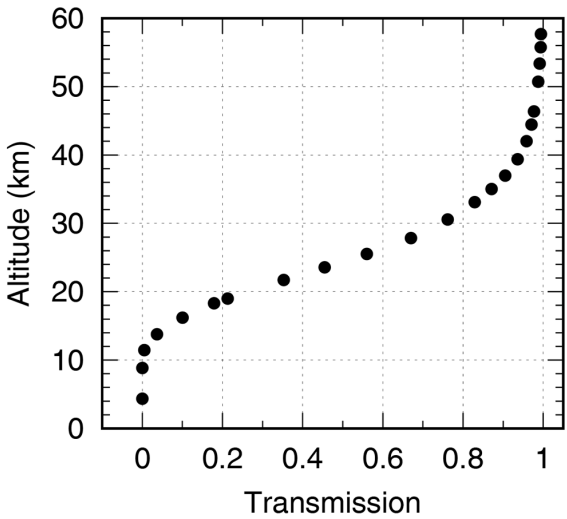

(d) $525 \mathrm{~nm}$ (corrected and selected)

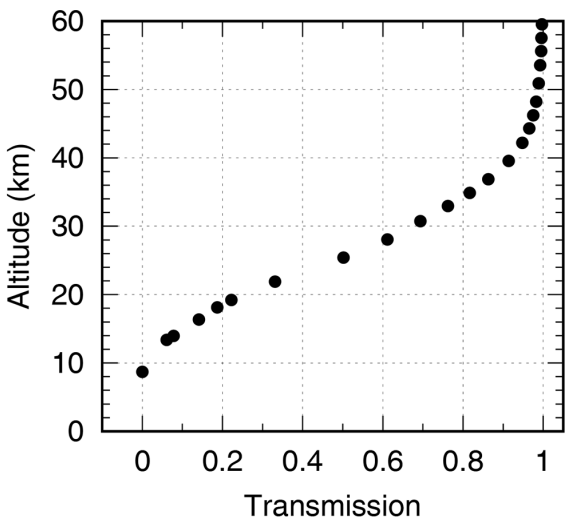

(f) $750 \mathrm{~nm}$ (corrected and selected)

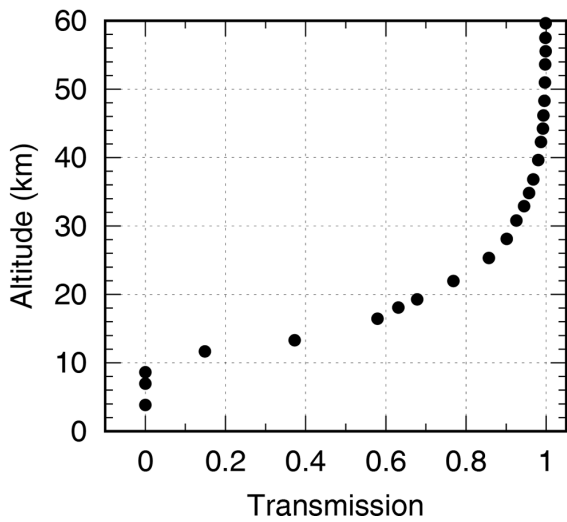

Figure 5. Transmissions for orbit 8014 (11 September 2003) and different wavelengths (top to bottom). (a, c, e) Uncorrected data (red) and selected subset (black). (b, d, f) Corrected and selected data.

aerosol extinction retrieval. This is the value for $25 \mathrm{~km}$; the complete profiles from 10 to $50 \mathrm{~km}$ are presented in Fig. $7 \mathrm{a}$. These profiles show the remaining transmission after effects of Rayleigh scattering and gas absorption have been subtracted. The difference to one can thus be interpreted as the effect of aerosol extinction.

The profiles of Fig. 7 are used as input for the aerosol extinction retrieval (see Sect. 4.2). The resulting aerosol ex- tinction profiles are given in Fig. 8. For comparison, we also plotted collocated SAGE-II (at 452 and $525 \mathrm{~nm}$ ) and SCIAMACHY limb aerosol extinction (at $750 \mathrm{~nm}$ ) profiles. In this case, the latitude and longitude of the SCIAMACHY measurement are at $61.9^{\circ} \mathrm{N}, 61.6^{\circ} \mathrm{W}$; the SAGE-II measurements took place about $535 \mathrm{~km} / 40 \mathrm{~min}$ apart from this. The SCIAMACHY limb measurement has a distance of $267 \mathrm{~km} /-6.6 \mathrm{~h}$ 
(a) $452 \mathrm{~nm}$

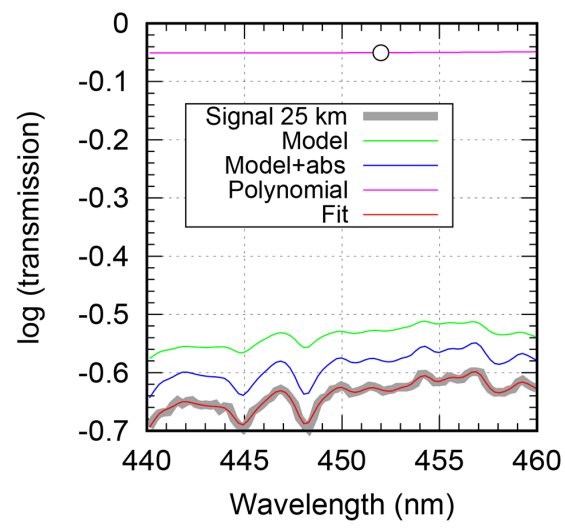

(c) $525 \mathrm{~nm}$

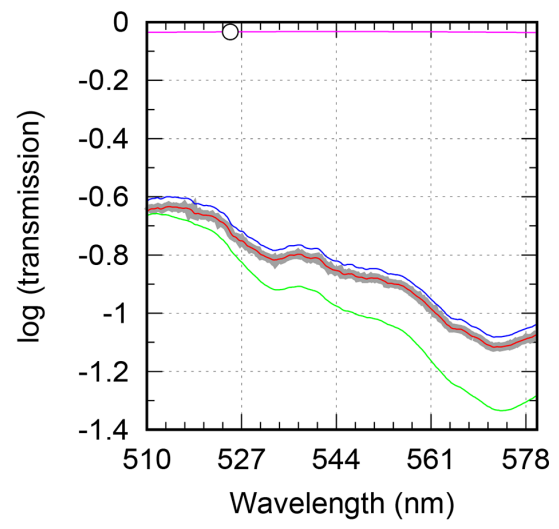

(e) $750 \mathrm{~nm}$

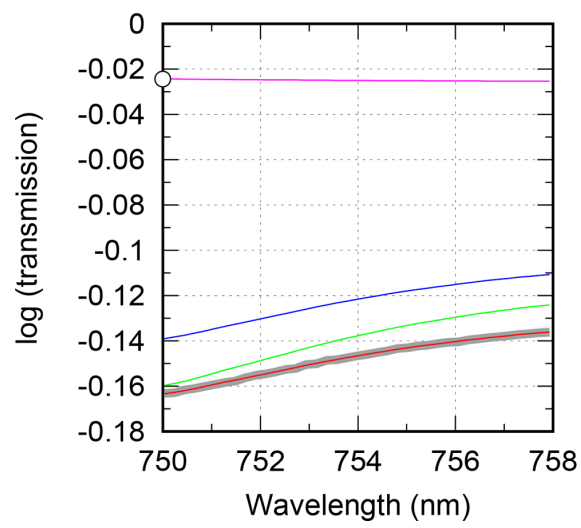

(b) $452 \mathrm{~nm}$

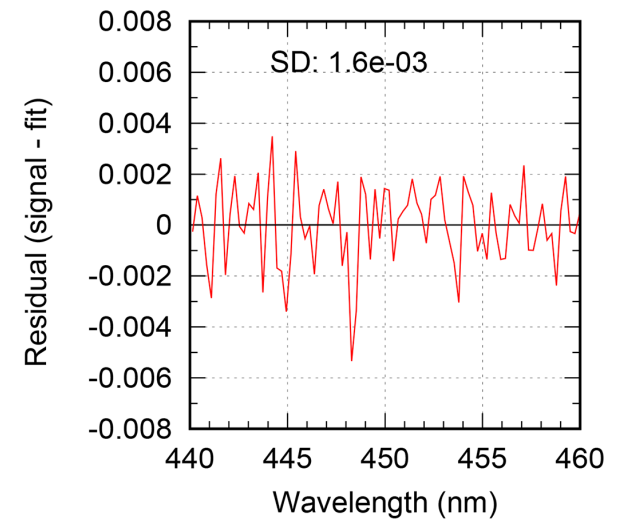

(d) $525 \mathrm{~nm}$

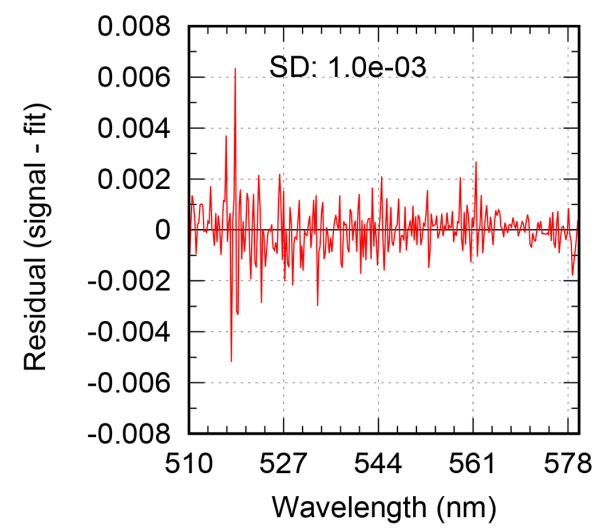

(f) $750 \mathrm{~nm}$

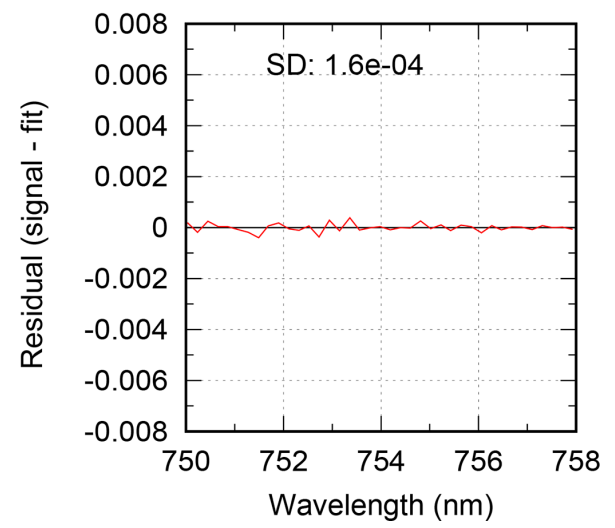

Figure 6. Example fit results for orbit 8014 (11 September 2003) and different wavelengths (a-f). (a, c, e) Spectrum at $25 \mathrm{~km}$ tangent height (thick grey line) and related fit results: the red line shows the total fit result, the green line the model spectrum, the blue line the model corrected for (fitted) absorptions and the pink line the (fitted) background polynomial. (b, d, f) Fit residual. The circle in the left plots marks the derived value for $P_{j}\left(\lambda_{\text {aer }}\right)$. SD indicates standard deviation.

The error bars correspond to the error given in the product files. For SCIAMACHY occultation, this error is derived from the propagation of the transmission errors (Fig. 7b). It does not consider any systematic contributions and is therefore only a lower estimate.
The overall agreement between SCIAMACHY occultation and SAGE-II is quite good. Above about $30 \mathrm{~km}$ transmissions are close to one (see Fig. 7). Thus, SCIAMACHY occultation errors typically increase and the retrieved aerosol extinctions become very noisy. Furthermore, at higher altitudes, vertical oscillations occur, which are artefacts proba- 

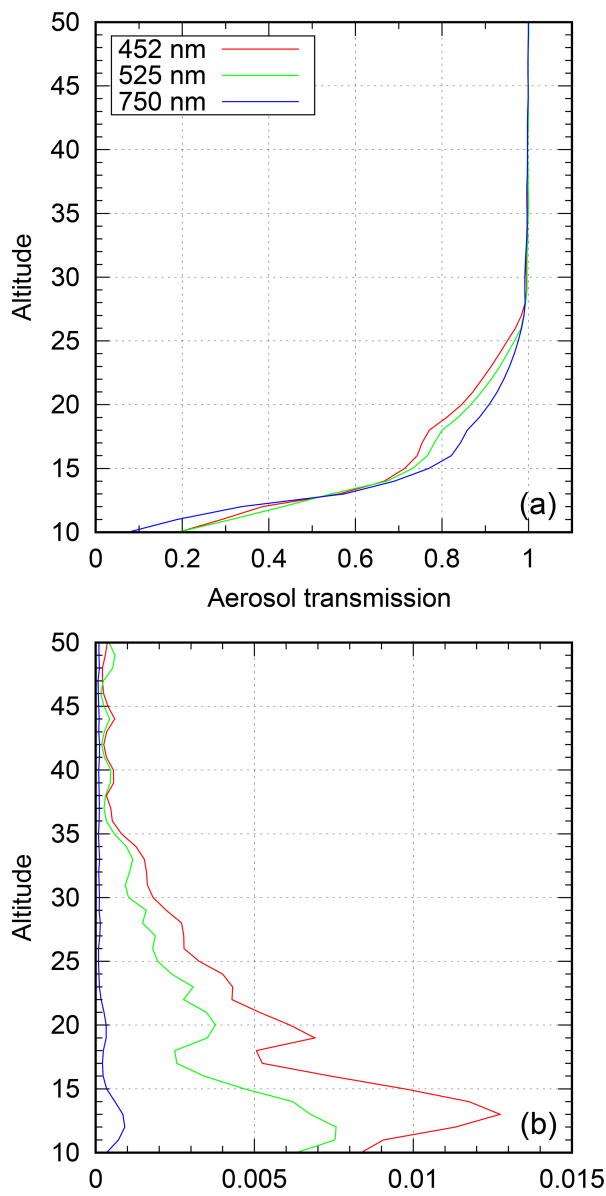

Figure 7. Aerosol transmissions (a) and corresponding errors (b) for orbit 8014 (11 September 2003) and different wavelengths.

bly introduced by the onion-peeling method; similar effects have been seen in greenhouse gas retrievals (see, e.g. Noël et al., 2018).

At $750 \mathrm{~nm}$, the retrieved SCIAMACHY limb and aerosol extinctions are also quite similar. The vertical sampling of the limb data is however much sparser. Noise and error of the occultation data are smaller; oscillations at higher altitudes are more pronounced than at lower wavelengths. The aerosol extinction minimum in the limb data at about $15 \mathrm{~km}$ is not seen in the occultation data.

\subsection{Validation}

In this section, we show the results of a comparison between the SCIAMACHY solar occultation v5.1.1 aerosol extinction data and corresponding profiles from other sensors, namely solar occultation data from SAGE-II and SAGE-III and limb profiles from SCIAMACHY and OSIRIS. For the comparisons, all aerosol extinction data are interpolated to the $1 \mathrm{~km}$ SCIAMACHY occultation data vertical grid. Only altitudes which are valid in both data sets are used; if not explicitly mentioned below, no additional filtering is applied. We com- (a) $452 \mathrm{~nm}$

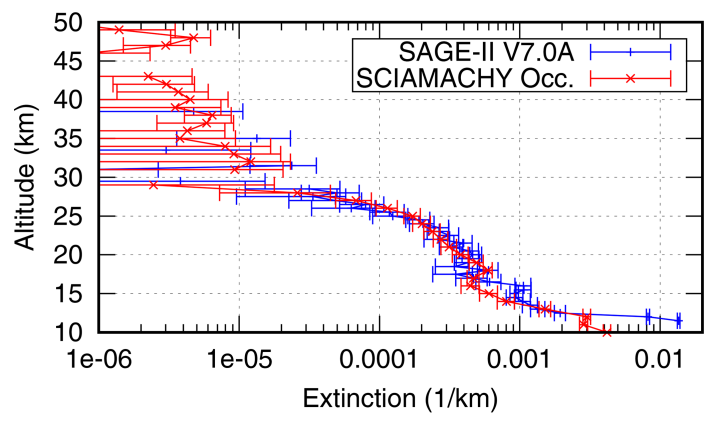

(b) $525 \mathrm{~nm}$

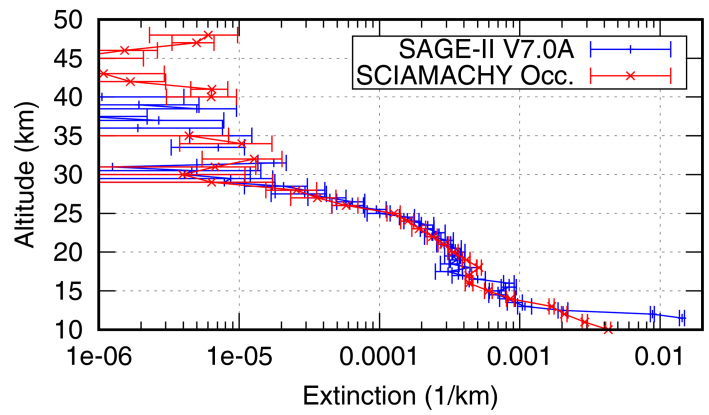

(c) $750 \mathrm{~nm}$

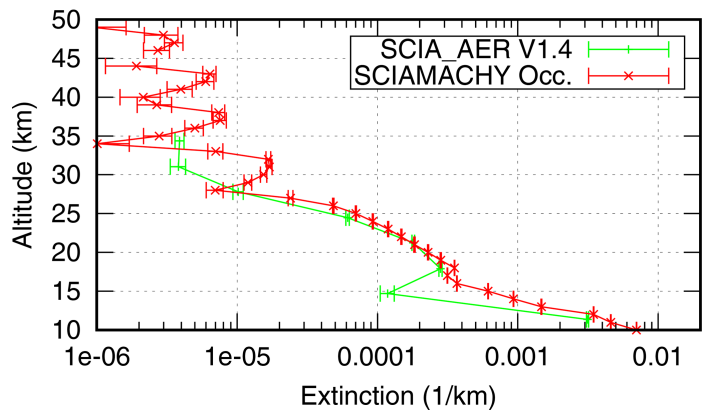

Figure 8. Retrieved aerosol extinction profiles from SCIAMACHY solar occultation (red), SAGE-II product v7.00A (blue) and SCIAMACHY limb aerosol extinction product v1.4 (green) for orbit 8014 (11 September 2003) and different wavelengths (a-c).

pute for all collocated data of each data set mean profiles and corresponding standard deviations. Then, we determine at each altitude the mean difference (SCIAMACHY - reference), the corresponding standard deviation of the difference and the mean of the error given in the SCIAMACHY product. These values are then divided by the mean aerosol extinction of both data sets to give relative values.

Because of the larger random and/or systematic errors at higher altitudes (see previous subsection), we currently consider only SCIAMACHY solar occultation aerosol extinction data below $30 \mathrm{~km}$ as reliable. In addition, SCIAMACHY occultation data below about $15 \mathrm{~km}$ have to be treated with care, as, e.g. the greenhouse gas occultation retrievals are known to give less accurate results there because of tropospheric influence not covered by the retrieval method (like increased 
refraction and strong vertical gradients at the tropopause). For the validation activities described in this section and later analyses, we will therefore concentrate on the altitude range of $15-30 \mathrm{~km}$.

\subsubsection{Comparison with SAGE-II}

The results from the comparison with SAGE-II at 452 and $525 \mathrm{~nm}$ are shown in Fig. 9.

Since aerosol extinctions exponentially decrease with altitude, mean differences and standard deviations of the differences decrease towards higher altitudes, whereas relative differences increase. In general, there is no obvious bias between the SCIAMACHY occultation results and the correlative data sets visible, but especially at $452 \mathrm{~nm}$, the mean occultation profile shows an oscillation with altitude which is not present in the SAGE-II data. This results in an oscillation of the differences with an amplitude of about 20\%-30\% and an estimated period of about $10 \mathrm{~km}$. For upper altitudes (above about $25 \mathrm{~km}$ ) at $525 \mathrm{~nm}$, this oscillation even causes mean differences larger than $50 \%$ to SAGE-II.

These kind of oscillating features have been observed in other ONPD products (see, e.g. Noël et al., 2018). It is assumed that these are related to the onion-peeling method which does not include, e.g. regularisation on these vertical scales.

The mean error of the SCIAMACHY occultation product is at all wavelengths smaller than the standard deviation of the differences, confirming that this error is indeed only a lower estimate. The standard deviation of the mean profiles is very similar for all comparisons. This indicates that all instruments and viewing geometries observe a comparable atmospheric variability.

\subsubsection{Comparison with SAGE-III}

The SAGE-III instrument on Meteor-3M provides aerosol extinction profiles at wavelengths close to those of the SCIAMACHY solar occultation product, which allows a direct comparison for all three wavelengths (see Fig. 10) with significantly more (5505) collocations than for SAGE-II for a similar time interval (2002 to 2005).

The results around $450 \mathrm{~nm}$ are very close to those obtained when comparing with SAGE-II. Between about 17 and $27 \mathrm{~km}$, SCIAMACHY and SAGE-III data agree within about $20 \%$. Above and below, deviations are larger (up to $60 \%$ at $30 \mathrm{~km}$ ), with SAGE-III aerosol extinctions being larger that those of SCIAMACHY. The oscillation features are also clearly visible.

Around $525 \mathrm{~nm}$, the agreement with SAGE-III is very good below about $24 \mathrm{~km}$; deviations are smaller than about $10 \%$ with only small oscillation. Above this altitude, oscillations increase, leading to differences of up to $50 \%-60 \%$.
At $750 \mathrm{~nm}$, there seems to be a systematic offset in the aerosol extinctions; SCIAMACHY data are about $30 \%-$ $50 \%$ higher.

Some small vertical oscillations are also visible here. Above about $25 \mathrm{~km}$, deviations start to increase up to values above $100 \%$ at $30 \mathrm{~km}$.

\subsubsection{Comparison with SCIAMACHY limb data}

For the comparison of SCIAMACHY occultation data with limb aerosol extinctions at $750 \mathrm{~nm}$, we divided the collocation data set into two parts corresponding to background conditions (defined by maximum aerosol extinctions below 0.001) and perturbed conditions (all others). The results are shown in Fig. 11.

Because of the large number of collocations, the error of the mean difference is very small (dotted and solid red lines are almost on top of each other).

For the background case, the comparison reveals almost perfect agreement between 20 and $25 \mathrm{~km}$; below $20 \mathrm{~km}$ and up to $27 \mathrm{~km}$, there is a small offset of $\pm 10 \%-20 \%$. Above $27 \mathrm{~km}$, differences start to increase, reaching about $80 \%$ at $30 \mathrm{~km}$. The standard deviations of the mean profiles are very similar for occultation and limb data, so variability is also comparable.

Under perturbed conditions, the atmospheric variability is much higher both in the spatial and temporal domains. The time offset of up to $10 \mathrm{~h}$ between occultation and limb measurements therefore results in a larger scatter between the two data sets and significantly increased standard deviations of differences and mean profiles of more than $100 \%$. This is why the lower limit lines of the standard deviations are not always visible in the logarithmic profile (Fig. 11d). The variability for limb is even larger than for occultation, possibly because occultation measurements occur always at the same local time (sunset). However, the average agreement of the two data sets is very good between about 17 and $27 \mathrm{~km}$ (deviation smaller than $10 \%$ ).

Below $17 \mathrm{~km}$, deviations up to $50 \%$ are observed. This is in line with comparisons of OSIRIS and SCIAMACHY limb aerosol extinctions with SAGE-II data (Rieger et al., 2018), which also revealed discrepancies of similar magnitude and sign at higher latitudes. It is assumed that these differences are due to the assumptions on particle sizes made in the limb retrievals, which are most crucial for high northern latitudes because of low scattering angles. This especially plays a role under perturbed conditions at lower altitudes, where the size distribution changes due to the insertion of volcanic particles. Perturbations in the particle amount and their sizes due to volcanic eruptions rapidly decrease with the altitude and usually do not reach above $20 \mathrm{~km}$ in the period from 2002 to 2012 .

Above $27 \mathrm{~km}$, deviations increase with occultation data being typically larger. This is most likely also related to oscillations in the occultation profiles (see Fig. 8). 

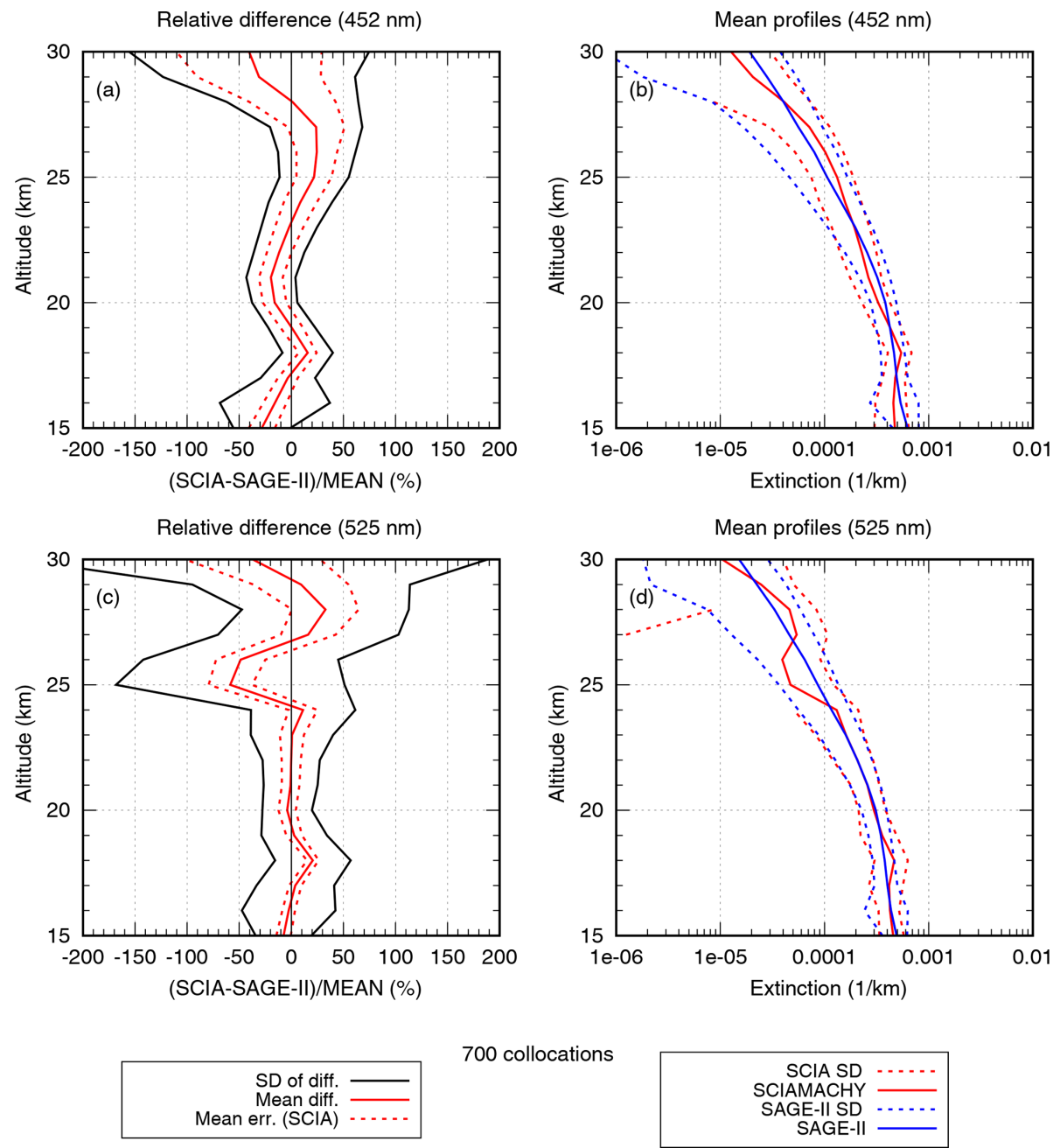

Figure 9. Comparison between aerosol extinction profiles from SCIAMACHY solar occultation and collocated SAGE-II data. (a) Relative differences at $452 \mathrm{~nm}$ (solid red), mean SCIAMACHY error (dashed red) and standard deviation of differences (black). (b) Mean aerosol extinction profiles at $452 \mathrm{~nm}$ (solid) and corresponding standard deviations (dashed) for SCIAMACHY (red) and SAGE-II (blue). (c) Same as panel (a) but for $525 \mathrm{~nm}$. (d) Same as panel (b) but for $525 \mathrm{~nm}$.

\subsubsection{Comparison with OSIRIS}

The results of a direct comparison with OSIRIS limb aerosol data at $750 \mathrm{~nm}$ shown in Fig. 12 reveal that the SCIAMACHY solar occultation aerosol extinctions are on average 20\%-30\% larger than those from OSIRIS, again with even larger differences above about $27 \mathrm{~km}$. This supports the assumption that the deviations at higher altitudes can be attributed to the SCIAMACHY data.

Results for disturbed and background conditions are similar in this case; this applies also to the variability (standard deviation of difference), which is on the order of $20 \%-30 \%$ with higher values at altitudes below $17 \mathrm{~km}$ and above $25 \mathrm{~km}$. This lower variability compared to SCIAMACHY limb data is due to the fact that the collocated OSIRIS data do not contain measurements at high latitudes in winter, where atmospheric variability is strongly increased by the polar vortex.
Furthermore, OSIRIS measurements at high northern latitudes are less affected by the assumed particle size distribution as they are done at scattering angles close to $90^{\circ}$ contrary to the forward-scattering conditions typical for SCIAMACHY limb measurements at these latitudes.

\section{Time series}

\subsection{Aerosol extinction time series}

The complete time series of SCIAMACHY solar occultation data has been processed for the three aerosol extinction wavelengths investigated in the present study. After filtering out invalid data (from times of non-nominal instrument performance, e.g. during decontamination periods) in total 43686 profiles (from August 2002 to April 2012) re- 

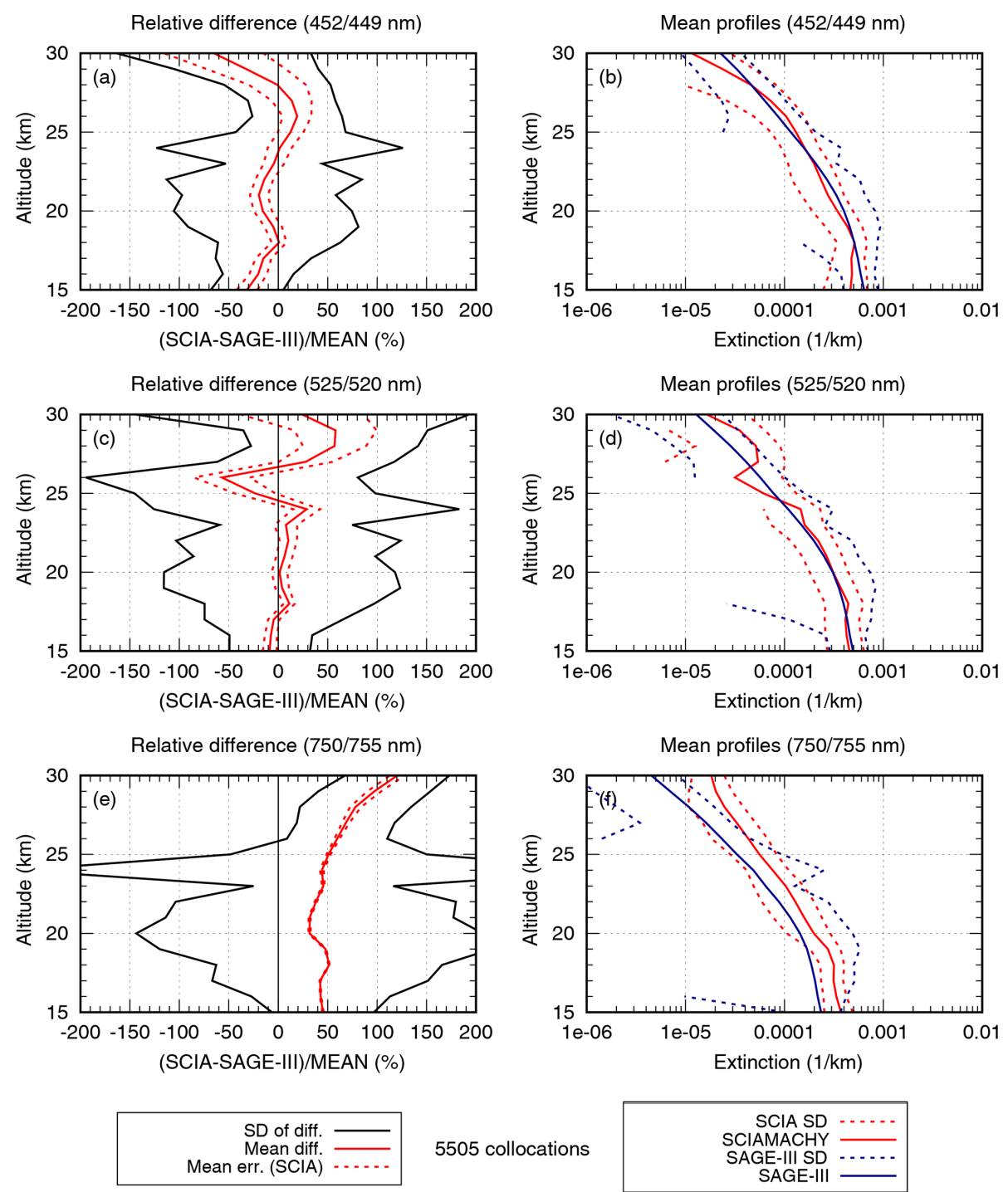

5505 collocations

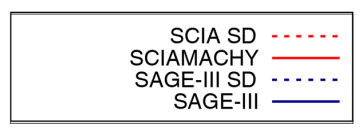

Figure 10. As Fig. 9 but for comparison with SAGE-III aerosol extinctions at 452/449, 525/520 and 750/755 nm (first wavelength is for SCIAMACHY, second for SAGE-III).

mained, from which daily average aerosol extinction profiles were created. Because of the Sun-synchronous Envisat orbit, all measurements of $1 \mathrm{~d}$ occur at essentially the same latitude but different longitudes. Thus, the geographic latitude of the measurements varies systematically with season and the daily averages are also zonal means (see also Noël et al., 2018). Higher latitudes $\left(\sim 65-70^{\circ}\right)$ typically occur in winter and lower latitudes $\left(\sim 50-60^{\circ}\right)$ in summer.

Figure 13 shows the resulting gridded time series from $\mathrm{Au}-$ gust 2002 to April 2012 for 452, 525 and $750 \mathrm{~nm}$ (top to bottom plots) from 15 to $30 \mathrm{~km}$. The colour scale is logarithmic, accounting for the typical exponential decrease of the aerosol extinction with altitude which is clearly visible in this figure at all wavelengths.

After 2008, there are some pronounced increases of aerosol extinction up to about 0.01 at lower altitudes visi- ble. These are caused be the eruption of volcanoes (marked by arrows) which reached into the stratosphere. In the case of the Nabro volcano, the eruption occurred at low latitudes $\left(13^{\circ} \mathrm{N}\right)$, but the plume was then transported to higher latitudes. The sudden increase due to upward transport of aerosol particles directly after the eruption is then followed by a gradual downward transport and decrease of aerosol extinction taking anywhere from several months up to 1 year. This can be seen at all wavelengths.

The observed aerosol extinctions also vary with season, which is partly caused by the systematic coupling between time and latitude mentioned above and the related variations in tropopause height. 

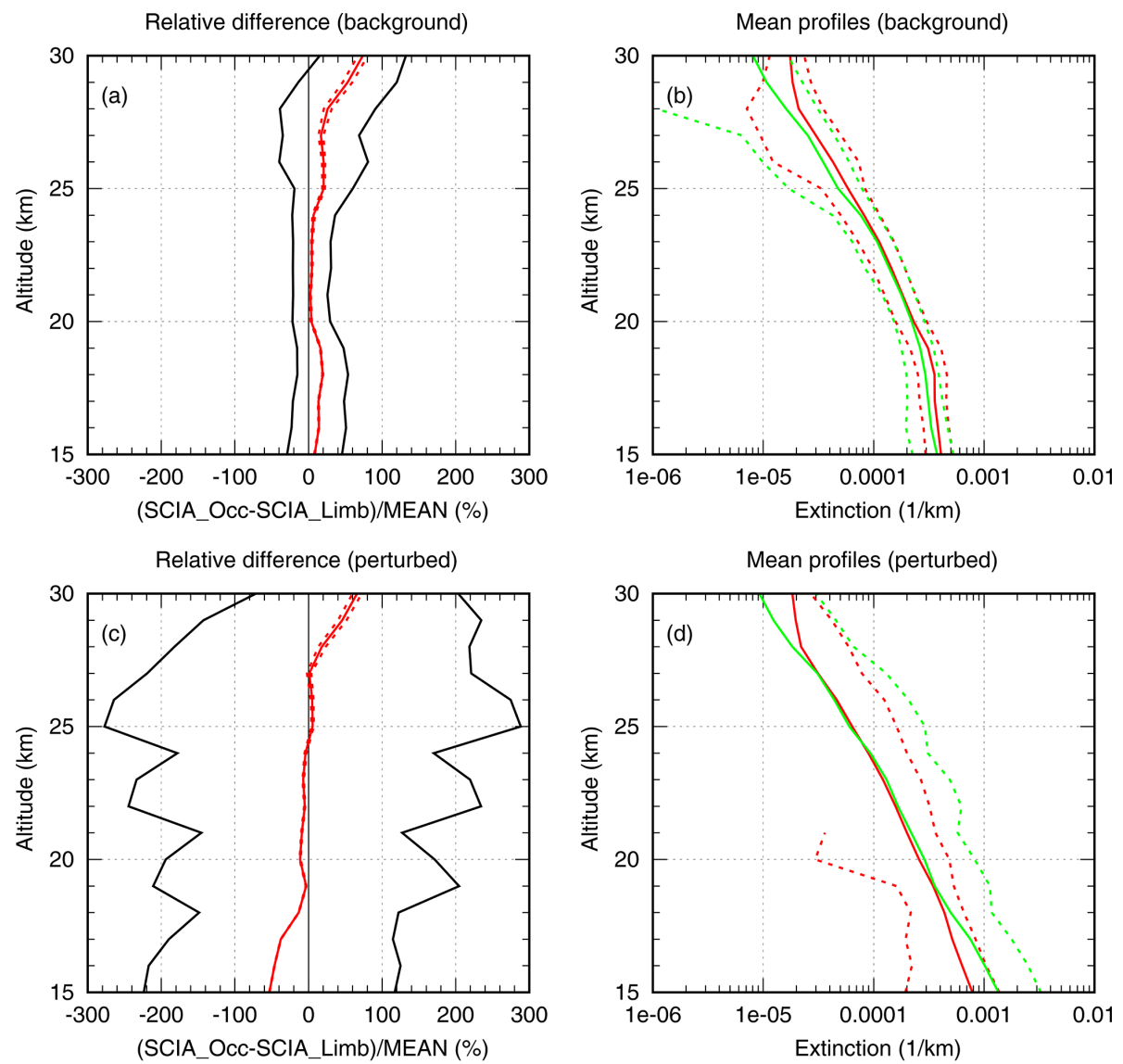

Background: 17271 collocations

Perturbed: 22691 collocations
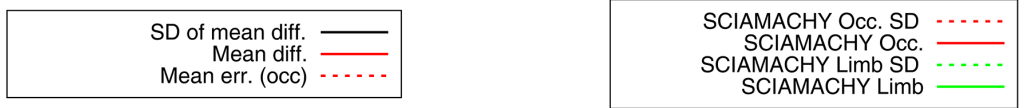

Figure 11. Similar to Fig. 9 but for $750 \mathrm{~nm}$ and comparison with SCIAMACHY limb aerosol extinctions. (a, b) Results for background times (i.e. aerosol extinctions always $<0.001)$. (c, d) Results for perturbed times (all other data).

\subsection{Anomalies}

To further investigate the temporal behaviour and to reduce the influence of possible systematic features in the data (e.g. vertical oscillations; see above), we computed monthly relative anomalies of the aerosol extinction. We concentrate here on the years 2003-2011 to avoid the possible influence of missing months in the first and last years on the weighting of data points.

For this, we first generated for each altitude monthly means from the daily average profiles. From these monthly averages, we then subtracted the 2003-2006 average value for each month to obtain absolute anomaly profiles. These data are then divided by the mean of the monthly average aerosol extinction profiles from 2003 to 2006 to remove the overall vertical shape of the aerosol extinction profiles (especially the exponential decrease with altitude). We do not use data after 2006 to determine the mean aerosol extinction profiles to avoid the influence of the prominent volcanic eruptions at lower altitudes (as seen in Fig. 13). The reference for the anomalies can therefore be interpreted as a "background time" mean.

The resulting relative anomalies may then be plotted using a common linear scale for all altitudes which facilitates the interpretation of the data. As already seen in the aerosol extinction plots (Fig. 13), aerosol extinctions increased during times of volcanic influence by more than a factor of 10 . These events are of course also clearly visible in the relative anomalies, but here we want to focus on smaller effects which cannot directly be inferred from the aerosol extinction time series. Therefore, we concentrate on the range of relative anomalies within \pm 4 . Figure 14 shows the monthly relative anomalies generated by the procedure described above using this scale. 

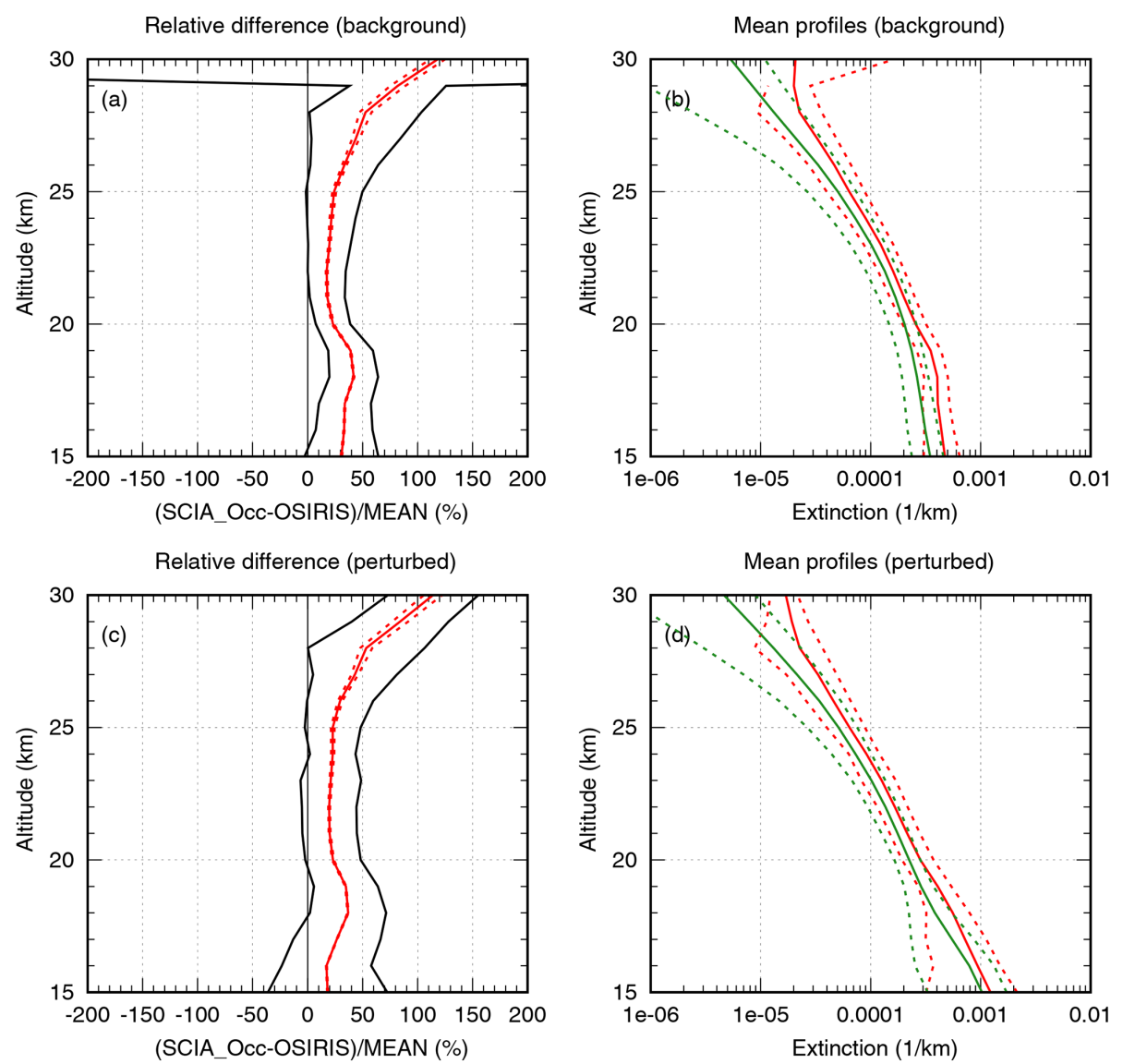

Background: 9003 collocations

Perturbed: 3105 collocations
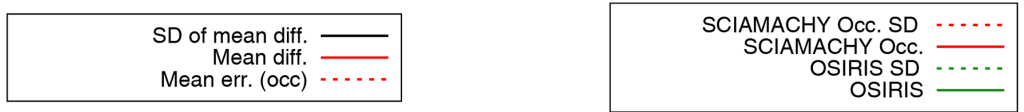

Figure 12. As Fig. 11 but for comparison with OSIRIS limb aerosol extinctions at $750 \mathrm{~nm}$.

Below $20 \mathrm{~km}$, in addition to the three periods of volcanic influence after mid-2008, the "background time" before 2007 can be clearly identified. During this time, interval relative anomalies are close to zero but slightly increasing with time.

Especially at the lower wavelengths, a small increase of relative aerosol extinction anomaly at the beginning of 2007 is observed. This is related to the influence of volcanic eruptions in the tropical region in 2006 (Soufrière Hills, Tavurvur) and later transport of particles to higher latitudes (see, e.g. von Savigny et al., 2015).

The $525 \mathrm{~nm}$ data show during January 2007 an oscillating structure between 16 and $19 \mathrm{~km}$. In fact, this feature is visible with different strength at all wavelengths. It is most likely induced by the presence of strong PSCs partly blocking the measured signal below $20 \mathrm{~km}$, which is supported by the time and location of the measurements (high latitudes in winter) and ECMWF data showing during this month at these altitudes temperatures below $195 \mathrm{~K}$ at which PSCs can be formed. In fact, the $750 \mathrm{~nm}$ plot shows several enhancements in wintertime (e.g. in January 2008, 2010 and 2011) between 20 and $30 \mathrm{~km}$, which we attribute to (in these cases, less strong) PSCs. The occurrence of PSCs at altitudes up to $30 \mathrm{~km}$ in January 2011 is quite unusual. It is confirmed also by CALIOP and MIPAS measurements and related to specific meteorological conditions during this winter leading, e.g. to a record ozone loss (see, e.g. Arnone et al., 2012; Khosrawi et al., 2016; Pitts et al., 2018).

Altitudes above $25 \mathrm{~km}$ show a regular pattern of alternating positive and negative anomalies with a period of about 2 years. This temporal variation is a transport effect assumed to be associated with the quasi-biennial oscillation (QBO); see, e.g. Baldwin et al. (2001).

Similar features can be seen in Fig. 15, which shows relative anomalies of the SCIAMACHY limb aerosol extinction data as a function of altitude and time. This plot is based on the complete set of about 40000 collocated limb profiles 

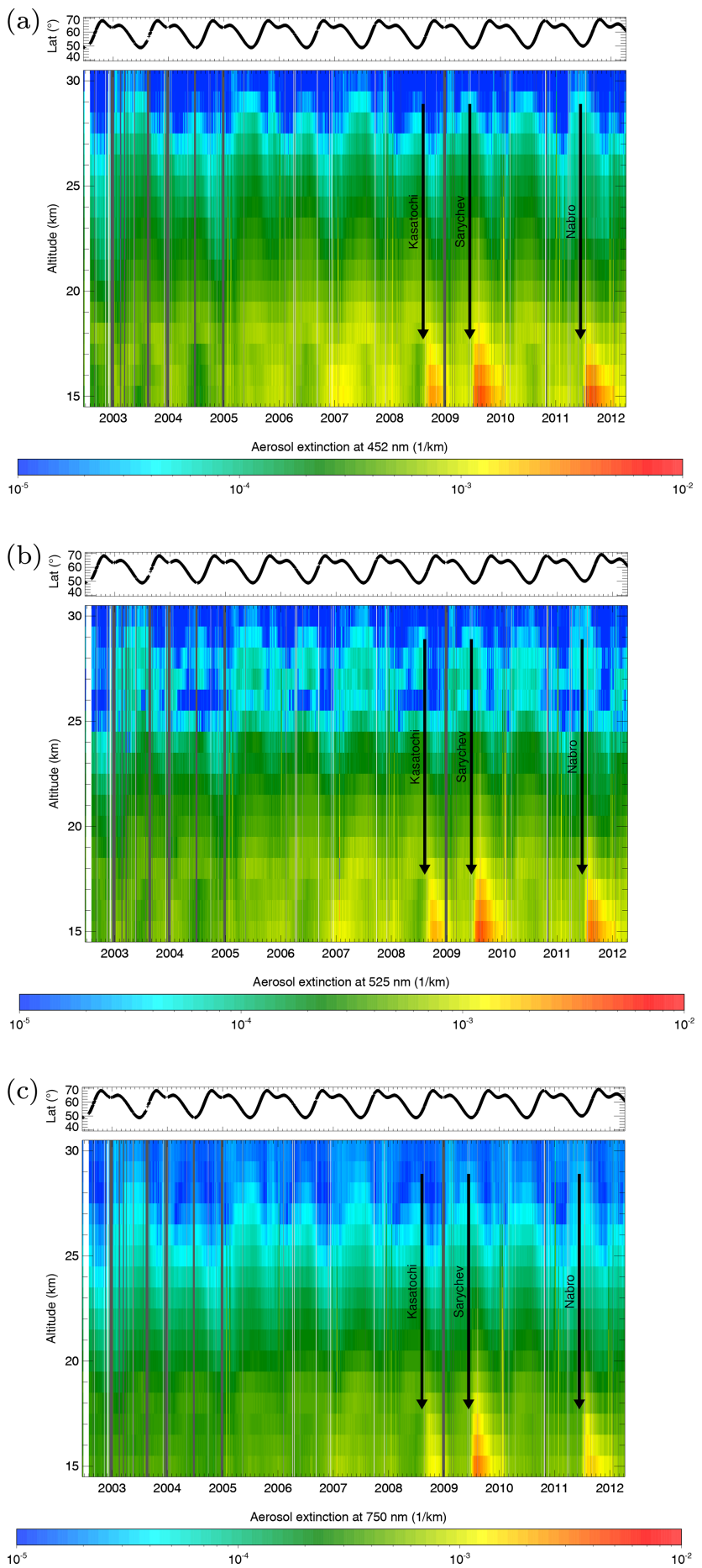

Figure 13. Time series of daily gridded aerosol extinction profiles from SCIAMACHY solar occultation at (a-c) 452, 525 and $750 \mathrm{~nm}$. The start times of some major volcanic eruptions occurring at higher latitudes are marked. At the top of each panel, the mean latitude of the observations is shown. Grey vertical bars in each panel denote times of degraded instrument performance (e.g. decontamination periods or switch-offs).
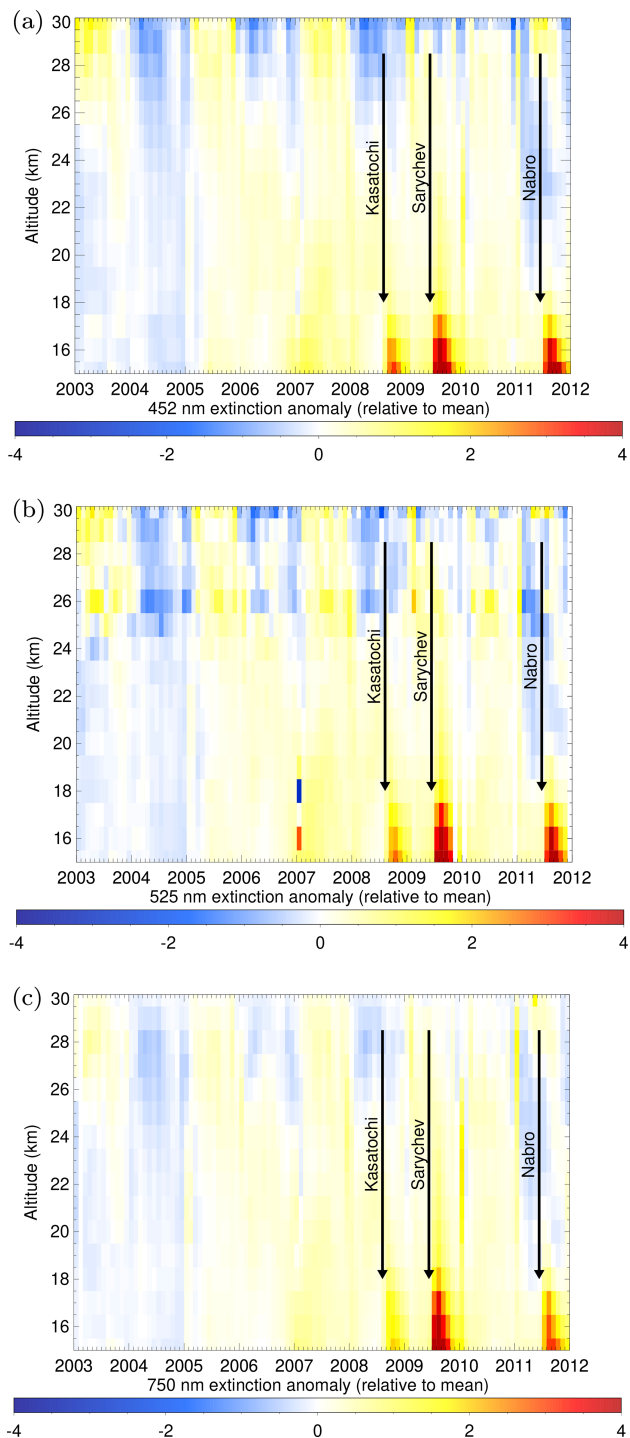

Figure 14. Time series of relative aerosol extinction anomalies from SCIAMACHY solar occultation at (from top to bottom) 452, 525 and $750 \mathrm{~nm}$. The start times of some major volcanic eruptions occurring at higher latitudes are marked.

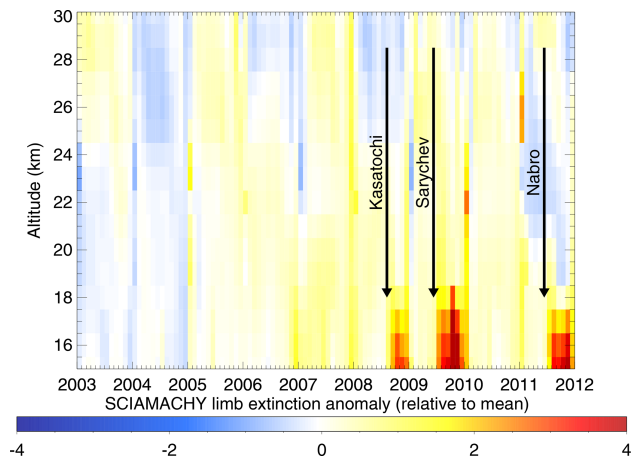

Figure 15. As Fig. 14 but for SCIAMACHY limb data at $750 \mathrm{~nm}$. 
(a) Extinction at $15 \mathrm{~km}$

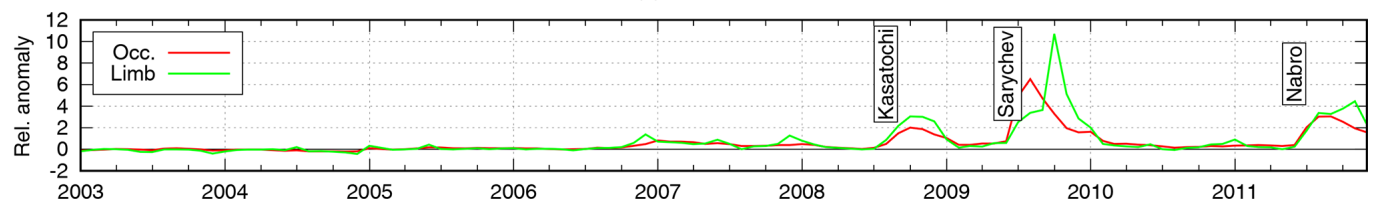

(b) Extinction at $20 \mathrm{~km}$

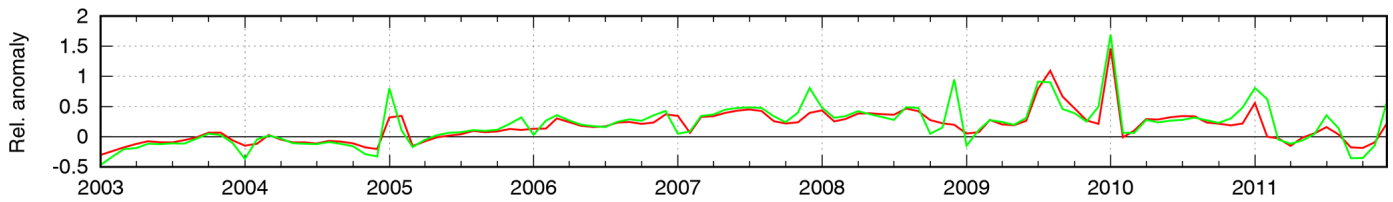

(c) Extinction at $25 \mathrm{~km}$

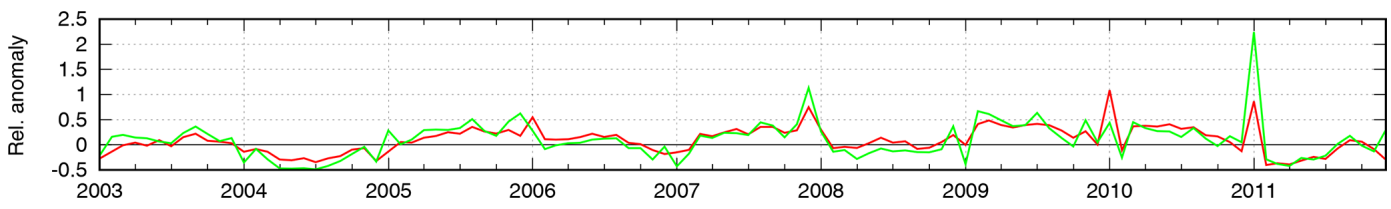

(d) Singapore monthly mean zonal wind at $10 \mathrm{hPa}$

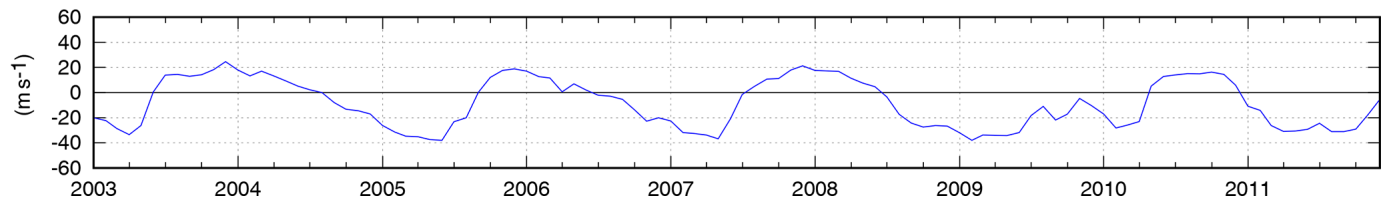

Figure 16. Time series of relative aerosol extinction anomalies at $750 \mathrm{~nm}$ for altitudes 15,20 and $25 \mathrm{~km}$ and Singapore monthly mean zonal wind at $10 \mathrm{hPa}$ (a-d). Red: SCIAMACHY solar occultation data. Green: SCIAMACHY limb data. Blue: zonal wind (as proxy for QBO).

used in the comparisons above (see Sect. 5.2). These limb data have been processed the same way as the occultation data to yield the anomalies.

The results for the limb aerosol extinctions are indeed very similar to occultation, but because of the larger variability of the limb data PSCs are more frequently visible in wintertime. Anomalies are also somewhat larger for volcanic events, which is in line with the validation results.

To further illustrate this, Fig. 16 shows corresponding time series at 15, 20 and $25 \mathrm{~km}$ together with Singapore monthly mean zonal wind data (Freie Universität Berlin, 2014), which are a proxy for QBO. Whereas the overall temporal behaviour of the limb and occultation data sets is very similar, individual events (PSCs, volcanic eruptions) are sometimes differently pronounced due to different measurement times and locations. The correlation with the zonal winds is also clearly visible. Note that there is a temporal shift between the time series which is related to the time required to transport air from the tropics (where winds are measured) to higher latitudes which may take - depending on altitude up to 8 years at $30 \mathrm{~km}$ (Haenel et al., 2015). A more detailed discussion on QBO and related transport effects (which are similar for trace gases and aerosols) is, e.g. given in Noël et al. (2018). Related results for SCIAMACHY limb data are shown in Brinkhoff et al. (2015).

\section{Conclusions}

Based on an improved radiometric calibration of SCIAMACHY solar occultation measurements and a newly developed onion-peeling retrieval method, a stratospheric aerosol extinction profile data set at 452,525 and $750 \mathrm{~nm}$ for the time interval of August 2002 to April 2012 could be derived. This data set covers the latitudinal region between about 50 and $70^{\circ} \mathrm{N}$ at a specific spatial and temporal sampling. Reasonable results are obtained between 15 and $30 \mathrm{~km}$.

Comparisons with SAGE-II data products at 452 and $525 \mathrm{~nm}$ show good agreement with essentially no mean bias but altitude-dependent differences on the order of $20 \%-$ $30 \%$. These differences are mainly due to unexpected vertical oscillations in the SCIAMACHY aerosol extinction profiles with a period of about $10 \mathrm{~km}$. It is assumed that these oscillations are caused by the onion-peeling retrieval method, as similar effects have been seen in the analysis of greenhouse gas profiles derived from SCIAMACHY solar occultation measurements (Noël et al., 2018). These findings are in principle confirmed by comparisons with SAGE-III data.

At $750 \mathrm{~nm}$, the results are less conclusive. The overall agreement with SCIAMACHY limb data at $750 \mathrm{~nm}$ is quite good between about 17 and $27 \mathrm{~km}(5 \%-10 \%)$. At higher and lower altitudes, deviations up to about $50 \%$ are observed, which are caused by oscillations in the occultation 
data (above $27 \mathrm{~km}$ ) and deficiencies of the limb data at higher latitudes (below $17 \mathrm{~km}$ ). The scatter in the data is especially large during perturbed (high-aerosol-load) conditions. Corresponding OSIRIS limb data show a similar behaviour but are typically about $25 \%$ lower than SCIAMACHY data. An even higher offset of up to $50 \%$ is derived for SAGE-III.

The observed oscillations become less prominent (amplitudes $<10 \%$ ) when comparing with data sets where a larger number of collocations are available covering longer times (e.g. SCIAMACHY limb and OSIRIS). They can be essentially removed by computation of anomalies.

Time series of SCIAMACHY solar occultation aerosol extinctions and related anomalies show the expected influence of major volcanic eruptions reaching the stratosphere, which causes a sudden increase of aerosol extinction by 1 order of magnitude or more below $20 \mathrm{~km}$, followed by a gradual decrease or downward transport over several months. Furthermore, some enhanced aerosol extinctions during polar wintertime were detected between 20 and $30 \mathrm{~km}$, which are attributed to the presence of PSCs.
A systematic variation of aerosol extinctions with season is observed, which is caused by the spatial-temporal coupling of the SCIAMACHY solar occultation measurements resulting in a regular variation of the tropopause height over the year. At altitudes above $25 \mathrm{~km}$, also QBO effects are seen, which is in line with the results of greenhouse gas studies (Noël et al., 2018).

These results show that the new SCIAMACHY solar occultation aerosol extinction data products are of reasonable quality and useful for geophysical interpretations. As for the corresponding greenhouse gas data, the quality of the products seems to be mainly limited by systematic effects, especially by vertical oscillations with a period of about $10 \mathrm{~km}$. This issue has been investigated for several years, but no solution could be found without significant reduction of the vertical resolution of the profiles. However, as we have shown in this study, the influence of these oscillations can be essentially removed by computation of anomalies. 


\section{Appendix A: Azimuth correction}

Switching to the Sun follower (SF) in azimuth at about $17 \mathrm{~km}$ tangent height may result in different azimuthal positions of the IFOV before or after the switch, resulting in a jump of the measured signal to a higher value. Azimuth mispointing may also occur due to a mismatch between the predicted (commanded) and true Sun position. This is only critical if the angular shift is so large that part of the Sun is not inside IFOV (see Fig. 2b). The effect on the signal due to this missing area can be corrected using the known position of the IFOV on the Sun (see above), but this requires the knowledge about the width of the IFOV. Unfortunately, there is not much information from SCIAMACHY on-ground calibration about the IFOV in solar occultation geometry, because this uses a smaller aperture than in the standard Earthshine measurements. This small aperture reduces the light by $3-$ 4 orders of magnitude, which makes measurements with typical on-ground light sources difficult, as they would require long integration times. Usually, a typical value of $0.72^{\circ}$ is given for the small aperture IFOV width (see, e.g Gottwald and Bovensmann, 2011).

To investigate the impact of azimuthal jumps in the signal after switching on the SF on the final aerosol product, we looked at discontinuities in the retrieved aerosol extinctions around $17 \mathrm{~km}$ as function of IFOV width. It turned out that only data a few kilometres around $17 \mathrm{~km}$ are affected by the azimuth jumps. The smoothest profiles are achieved when assuming an IFOV width of $0.68^{\circ}$, which is why we used this value in our study.

\section{Appendix B: Bending angle fit}

The underlying assumption for the determination of the bending angle is that the atmosphere does not change during one occultation measurement. This, however, is a general assumption of the retrieval method. The bending angle can then be determined using the fact that altitudes of adjacent upward/downward scans overlap. This is illustrated in Fig. B1, which shows as an example the (uncorrected) measured transmissions $T_{1}^{\mathrm{m}}$ and $T_{2}^{\mathrm{m}}$ of two upward scans (nos. 18 and 20). These two measurements are centred around different tangent heights, but the covered altitude ranges overlap. Let $P_{1}$ be the point where the transmission of scan 18 is highest. This occurs at a tangent altitude $z_{1}$ of about $33.5 \mathrm{~km}$. If we interpolate the transmissions of scan 20 to this altitude, we get point $P_{2}$. The points $\left(P_{1}, P_{2}\right)$ therefore correspond to an observation of the same tangent altitude but for different viewing directions $\left(\gamma_{1}, \gamma_{2}\right)$ and for different Sun positions $\left(\beta_{1}, \beta_{2}\right)$. Since the observed point in the atmosphere is the same, the scan-corrected transmissions should also be the same, i.e.

$T_{1}\left(z_{1}\right)=T_{2}\left(z_{1}\right)$.

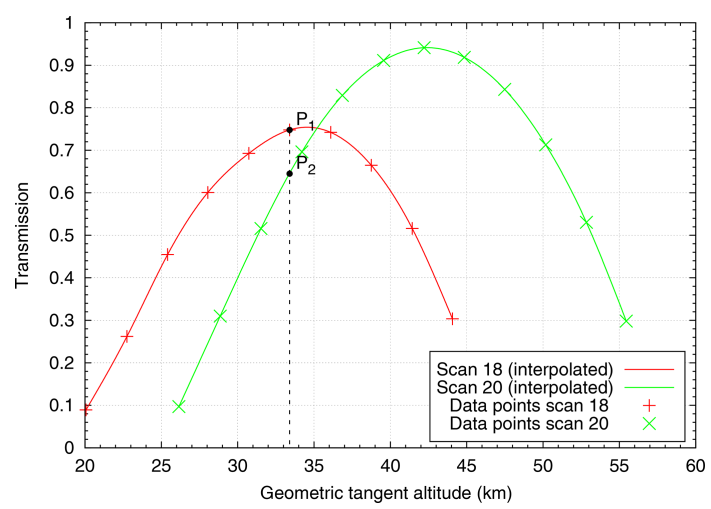

Figure B1. Bending angle fit. See text for explanation.

The fact that we observe different transmissions $\left(T_{1}^{\mathrm{m}}\left(z_{1}\right)>\right.$ $\left.T_{2}^{\mathrm{m}}\left(z_{1}\right)\right)$ is due to refraction, i.e. the (same) bending angle $\delta\left(z_{1}\right)$ at this altitude.

Combining Eqs. (B1) and (3) leads to

$\frac{T_{1}^{\mathrm{m}}\left(z_{1}\right)}{T_{2}^{\mathrm{m}}\left(z_{1}\right)}=\frac{S\left(\gamma_{1}-\beta_{1}-\delta\left(z_{1}\right)\right)}{S\left(\gamma_{2}-\beta_{2}-\delta\left(z_{1}\right)\right)}$.

This equation can be solved numerically to derive $\delta\left(z_{1}\right)$. In principle, this procedure can be applied to all pairs of scans; however, it is practically limited by the low transmissions at lower altitudes and too small refraction at higher altitudes. We therefore restrict the application to the altitude range 15 to $35 \mathrm{~km}$, which gives us about five data points of $\delta$ for different tangent altitudes $z$.

We then fit a straight line to $\log \delta(z)$ to derive the parameters $a$ and $b$ from Eq. (1). This is done independently for each considered wavelength. An example of this is shown in Fig. B2. 


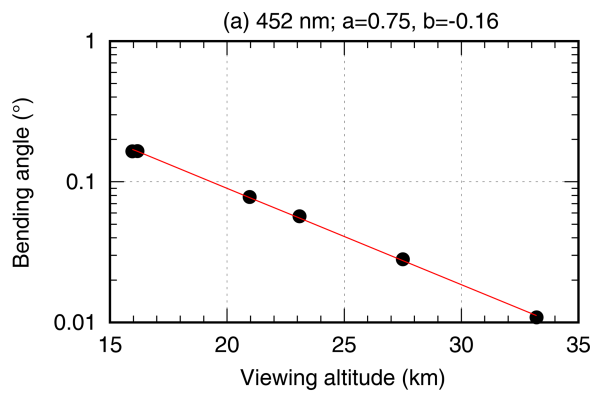

(b) $525 \mathrm{~nm}$; $\mathrm{a}=0.82, \mathrm{~b}=-0.16$

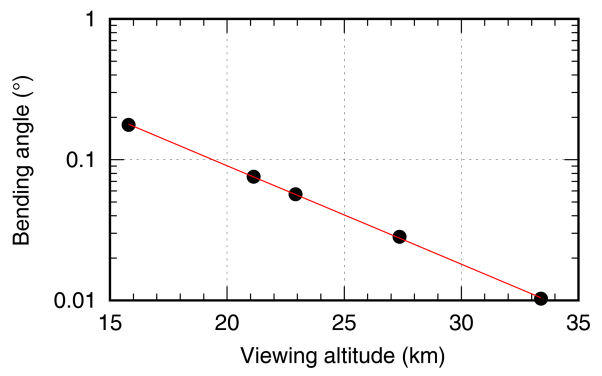

(c) $750 \mathrm{~nm} ; \mathrm{a}=0.65, \mathrm{~b}=-0.15$

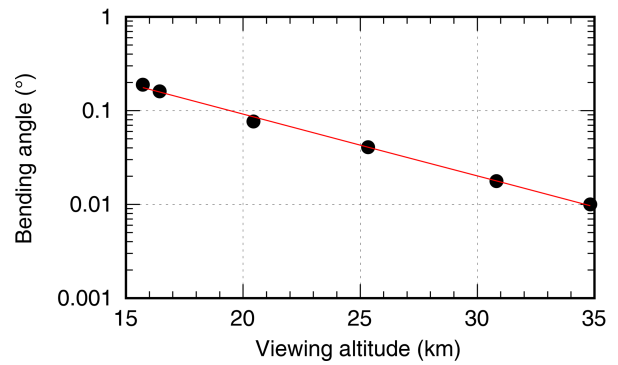

Figure B2. Fit of bending angle parameters $a$ and $b$ for different wavelengths. 
Data availability. The SCIAMACHY solar occultation aerosol extinction data presented in this work (v5.1.1) are available on request from the authors.

Author contributions. SN developed the calibration and retrieval methods, generated the SCIAMACHY occultation aerosol extinction data set and performed the analysis of the data. $\mathrm{KB}$ provided the pointing corrections for the data. AR and EM produced the SCIAMACHY limb aerosol extinction data set. All authors (including HB and JPB) contributed to the preparation of the manuscript.

Competing interests. The authors declare that they have no conflict of interest.

Acknowledgements. SCIAMACHY data have been provided by ESA. We thank the European Centre for Medium-Range Weather Forecasts (ECMWF) for providing us with analysed meteorological fields. SAGE-II data were obtained from the NASA Langley Research Center Atmospheric Science Data Center. This work has been funded by DLR-Bonn (SADOS-III project), ESA (SQWG-III project), the University of Bremen and partially by DFG through the research unit VolImpact.

Financial support. This research has been supported by the Deutsches Zentrum für Luft- und Raumfahrt (grant no. 50EE1105), the European Space Agency (grant no. 4000112017/14/I-AM) and the Deutsche Forschungsgemeinschaft (grant no. FOR 2820).

The article processing charges for this open-access publication were covered by the University of Bremen.

Review statement. This paper was edited by Omar Torres and reviewed by two anonymous referees.

\section{References}

Arnone, E., Castelli, E., Papandrea, E., Carlotti, M., and Dinelli, B. M.: Extreme ozone depletion in the 2010-2011 Arctic winter stratosphere as observed by MIPAS/ENVISAT using a 2D tomographic approach, Atmos. Chem. Phys., 12, 9149-9165, https://doi.org/10.5194/acp-12-9149-2012, 2012.

Baldwin, M. P., Gray, L. J., Dunkerton, T. J., Hamilton, K., Haynes, P. H., Randel, W. J., Holton, J. R., Alexander, M. J., Hirota, I., Horinouchi, T., Jones, D. B. A., Kinnersley, J. S., Marquardt, C., Sato, K., and Takahashi, M.: The quasi-biennial oscillation, Rev. Geophys., 39, 179-229, https://doi.org/10.1029/1999RG000073, 2001.

Bevilacqua, R. M., Hoppel, K. W., Hornstein, J. S., Lucke, R. L., Shettle, E. P., Ainsworth, T. L., Debrestian, D., Fromm, M. D., Krigman, S. S., Lumpe, J., Glaccum, W., Olivero, J. J., Clancy, R. T., Randall, C. E., Rusch, D. W., Chassefière, E., Dalaudier, F., Deniel, C., Brogniez, C., and Leno- ble, J.: First results from POAM II: The dissipation of the 1993 Antarctic Ozone Hole, Geophys. Res. Lett., 22, 909-912, https://doi.org/10.1029/95GL00535, 1995.

Bourassa, A. E., Rieger, L. A., Lloyd, N. D., and Degenstein, D. A.: Odin-OSIRIS stratospheric aerosol data product and SAGE III intercomparison, Atmos. Chem. Phys., 12, 605-614, https://doi.org/10.5194/acp-12-605-2012, 2012.

Bramstedt, K., Stone, T. C., Gottwald, M., Noël, S., Bovensmann, H., and Burrows, J. P.: Improved pointing information for SCIAMACHY from in-flight measurements of the viewing directions towards sun and moon, Atmos. Meas. Tech., 10, 2413-2423, https://doi.org/10.5194/amt-10-2413-2017, 2017.

Brinkhoff, L. A., Rozanov, A., Hommel, R., von Savigny, C., Ernst, F., Bovensmann, H., and Burrows, J. P.: Ten-year SCIAMACHY stratospheric aerosol data record: Signature of the secondary meridional circulation associated with the quasibiennial oscillation, in: Towards an Interdisciplinary Approach in Earth System Science, edited by: Lohmann, G., Meggers, H., Unnithan, V., Wolf-Gladrow, D., Notholt, J., and Bracher, A., Springer International Publishing, Switzerland, 4958, https://doi.org/10.1007/978-3-319-13865-7_6, 2015.

Chen, Z., Bhartia, P. K., Loughman, R., Colarco, P., and DeLand, M.: Improvement of stratospheric aerosol extinction retrieval from OMPS/LP using a new aerosol model, Atmos. Meas. Tech., 11, 6495-6509, https://doi.org/10.5194/amt-116495-2018, 2018.

Chu, W. P. and McCormick, M. P.: Inversion of stratospheric aerosol and gaseous constituents from spacecraft solar extinction data in the 0.38-1.0- $\mu \mathrm{m}$ wavelength region, Appl. Optics, 18, 14041413, https://doi.org/10.1364/AO.18.001404, 1979.

Cisewski, M., Zawodny, J., Gasbarre, J., Eckman, R., Topiwala, N., Rodriguez-Alvarez, O., Cheek, D., and Hall, S.: The Stratospheric Aerosol and Gas Experiment (SAGE III) on the International Space Station (ISS) Mission, in: Sensors, Systems, and Next-Generation Satellites XVIII, vol. 9241, edited by: Meynart, R., Neeck, S. P., and Shimoda, H., International Society for Optics and Photonics, SPIE, 59-65, https://doi.org/10.1117/12.2073131, 2014.

Coldewey-Egbers, M., Weber, M., Lamsal, L. N., de Beek, R., Buchwitz, M., and Burrows, J. P.: Total ozone retrieval from GOME UV spectral data using the weighting function DOAS approach, Atmos. Chem. Phys., 5, 1015-1025, https://doi.org/10.5194/acp-5-1015-2005, 2005.

Damadeo, R. P., Zawodny, J. M., Thomason, L. W., and Iyer, N.: SAGE version 7.0 algorithm: application to SAGE II, Atmos. Meas. Tech., 6, 3539-3561, https://doi.org/10.5194/amt-6-35392013, 2013.

Dee, D. P., Uppala, S. M., Simmons, A. J., Berrisford, P., Poli, P., Kobayashi, S., Andrae, U., Balmaseda, M. A., Balsamo, G., Bauer, P., Bechtold, P., Beljaars, A. C. M., van de Berg, L., Bidlot, J., Bormann, N., Delsol, C., Dragani, R., Fuentes, M., Geer, A. J., Haimberger, L., Healy, S. B., Hersbach, H., Hólm, E. V., Isaksen, L., Kållberg, P., Köhler, M., Matricardi, M., McNally, A. P., Monge-Sanz, B. M., Morcrette, J.-J., Park, B.-K., Peubey, C., de Rosnay, P., Tavolato, C., Thépaut, J.-N., and Vitart, F.: The ERA-Interim reanalysis: configuration and performance of the data assimilation system, Q. J. Roy. Meteorol. Soc., 137, 553597, https://doi.org/10.1002/qj.828, 2011. 
Fischer, H., Birk, M., Blom, C., Carli, B., Carlotti, M., von Clarmann, T., Delbouille, L., Dudhia, A., Ehhalt, D., Endemann, M., Flaud, J. M., Gessner, R., Kleinert, A., Koopman, R., Langen, J., López-Puertas, M., Mosner, P., Nett, H., Oelhaf, H., Perron, G., Remedios, J., Ridolfi, M., Stiller, G., and Zander, R.: MIPAS: an instrument for atmospheric and climate research, Atmos. Chem. Phys., 8, 2151-2188, https://doi.org/10.5194/acp-8-21512008, 2008.

Freie Universität Berlin: Die Quasi-Biennial-Oszillation (QBO) Datenreihe, Fachbereich Geowissenschaften/Institut für Meteorologie, AG Atmosphärendynamik, available at: http://www. geo.fu-berlin.de/met/ag/strat/produkte/qbo/index.html, last access: 9 July 2014.

Gottwald, M. and Bovensmann, H. (Eds.): SCIAMACHY - Exploring the Changing Earth's Atmosphere, Springer, Dordrecht, Heidelberg, London, New York, https://doi.org/10.1007/978-90481-9896-2, 2011.

Haenel, F. J., Stiller, G. P., von Clarmann, T., Funke, B., Eckert, E., Glatthor, N., Grabowski, U., Kellmann, S., Kiefer, M., Linden, A., and Reddmann, T.: Reassessment of MIPAS age of air trends and variability, Atmos. Chem. Phys., 15, 13161-13176, https://doi.org/10.5194/acp-15-13161-2015, 2015.

Jaross, G., Bhartia, P. K., Chen, G., Kowitt, M., Haken, M., Chen, Z., Xu, P., Warner, J., and Kelly, T.: OMPS Limb Profiler instrument performance assessment, J. Geophys. Res.-Atmos., 119, 4399-4412, https://doi.org/10.1002/2013JD020482, 2014.

Kar, J., Lee, K.-P., Vaughan, M. A., Tackett, J. L., Trepte, C. R., Winker, D. M., Lucker, P. L., and Getzewich, B. J.: CALIPSO level 3 stratospheric aerosol profile product: version 1.00 algorithm description and initial assessment, Atmos. Meas. Tech., 12, 6173-6191, https://doi.org/10.5194/amt-12-6173-2019, 2019.

Kent, G. S. and McCormick, M. P.: SAGE and SAM II Measurements of Global Stratospheric Aerosol Optical Depth and Mass Loading, J. Geophys. Res., 89, 5303-5314, 1984.

Khosrawi, F., Urban, J., Lossow, S., Stiller, G., Weigel, K., Braesicke, P., Pitts, M. C., Rozanov, A., Burrows, J. P., and Murtagh, D.: Sensitivity of polar stratospheric cloud formation to changes in water vapour and temperature, Atmos. Chem. Phys., 16, 101-121, https://doi.org/10.5194/acp-16-101-2016, 2016.

Kyrölä, E., Tamminen, J., Sofieva, V., Bertaux, J. L., Hauchecorne, A., Dalaudier, F., Fussen, D., Vanhellemont, F., Fanton d'Andon, O., Barrot, G., Guirlet, M., Mangin, A., Blanot, L., Fehr, T., Saavedra de Miguel, L., and Fraisse, R.: Retrieval of atmospheric parameters from GOMOS data, Atmos. Chem. Phys., 10, 1188111903, https://doi.org/10.5194/acp-10-11881-2010, 2010.

Lee, K.-M., Park, J. H., Massie, S. T., and Choi, W.: Extinction coefficients and properties of Pinatubo aerosol determined from Halogen Occultation Experiment (HALOE) data, J. Geophys. Res.-Atmos., 106, 28333-28345, https://doi.org/10.1029/2000JD000251, 2001.

Llewellyn, E. J., Lloyd, N. D., Degenstein, D. A., Gattinger, R. L., Petelina, S. V., Bourassa, A. E., Wiensz, J. T., Ivanov, E. V., McDade, I. C., Solheim, B. H., McConnell, J. C., Haley, C. S., von Savigny, C., Sioris, C. E., McLinden, C. A., Griffioen, E., Kaminski, J., Evans, W. F., Puckrin, E., Strong, K., Wehrle, V., Hum, R. H., Kendall, D. J., Matsushita, J., Murtagh, D. P., Brohede, S., Stegman, J., Witt, G., Barnes, G., Payne, W. F., Piché, L., Smith, K., Warshaw, G., Deslauniers, D. L., Marchand, P., Richardson, E. H., King, R. A., Wevers, I., McCreath,
W., Kyrölä, E., Oikarinen, L., Leppelmeier, G. ., Auvinen, H., Mégie, G., Hauchecorne, A., Lefèvre, F., de La Nöe, J., Ricaud, P., Frisk, U., Sjoberg, F., von Schéele, F., and Nordh, L.: The OSIRIS instrument on the Odin spacecraft, Can. J. Phys., 82, 411-422, https://doi.org/10.1139/p04-005, 2004.

Loughman, R., Bhartia, P. K., Chen, Z., Xu, P., Nyaku, E., and Taha, G.: The Ozone Mapping and Profiler Suite (OMPS) Limb Profiler (LP) Version 1 aerosol extinction retrieval algorithm: theoretical basis, Atmos. Meas. Tech., 11, 2633-2651, https://doi.org/10.5194/amt-11-2633-2018, 2018.

Malinina, E., Rozanov, A., Rozanov, V., Liebing, P., Bovensmann, H., and Burrows, J. P.: Aerosol particle size distribution in the stratosphere retrieved from SCIAMACHY limb measurements, Atmos. Meas. Tech., 11, 2085-2100, https://doi.org/10.5194/amt-11-2085-2018, 2018.

McCormick, M. P.: SAGE II: An overview, Adv. Space Res., 7, 219-226, 1987.

McElroy, C. T., Nowlan, C. R., Drummond, J. R., Bernath, P. F., Barton, D. V., Dufour, D. G., Midwinter, C., Hall, R. B., Ogyu, A., Ullberg, A., Wardle, D. I., Kar, J., Zou, J., Nichitiu, F., Boone, C. D., Walker, K. A., and Rowlands, N.: The ACE-MAESTRO instrument on SCISAT: description, performance, and preliminary results, Appl. Optics, 46, 4341-4356, https://doi.org/10.1364/AO.46.004341, 2007.

NASA: U.S. Standard Atmosphere Supplements, Tech. rep., US Government Printing Office, Washington, D.C., 1976.

Noël, S., Bramstedt, K., Rozanov, A., Bovensmann, H., and Burrows, J. P.: Water vapour profiles from SCIAMACHY solar occultation measurements derived with an onion peeling approach, Atmos. Meas. Tech., 3, 523-535, https://doi.org/10.5194/amt-3523-2010, 2010.

Noël, S., Bramstedt, K., Rozanov, A., Bovensmann, H., and Burrows, J. P.: Stratospheric methane profiles from SCIAMACHY solar occultation measurements derived with onion peeling DOAS, Atmos. Meas. Tech., 4, 2567-2577, https://doi.org/10.5194/amt-4-2567-2011, 2011.

Noël, S., Bramstedt, K., Hilker, M., Liebing, P., Plieninger, J., Reuter, M., Rozanov, A., Sioris, C. E., Bovensmann, H., and Burrows, J. P.: Stratospheric $\mathrm{CH}_{4}$ and $\mathrm{CO}_{2}$ profiles derived from SCIAMACHY solar occultation measurements, Atmos. Meas. Tech., 9, 1485-1503, https://doi.org/10.5194/amt-9-1485-2016, 2016.

Noël, S., Weigel, K., Bramstedt, K., Rozanov, A., Weber, M., Bovensmann, H., and Burrows, J. P.: Water vapour and methane coupling in the stratosphere observed using SCIAMACHY solar occultation measurements, Atmos. Chem. Phys., 18, 4463-4476, https://doi.org/10.5194/acp-18-4463-2018, 2018.

Osborn, M. T., Rosen, J. M., McCormick, M. P., Wang, P.-H., Livingston, J. M., and Swissler, T. J.: SAGE II Aerosol Correlative Observations: Profile Measurements, J. Geophys. Res., 94, 8353-8366, 1989.

Pitts, M. C., Poole, L. R., and Gonzalez, R.: Polar stratospheric cloud climatology based on CALIPSO spaceborne lidar measurements from 2006 to 2017, Atmos. Chem. Phys., 18, 1088110913, https://doi.org/10.5194/acp-18-10881-2018, 2018.

Randall, C. E., Rusch, D. W., Olivero, J. J., Bevilacqua, R. M., Poole, L. R., Lumpe, J. D., Fromm, M. D., Hoppel, K. W., Hornstein, J. S., and Shettle, E. P.: An overview of POAM II aerosol 
measurments at $1.06 \mu \mathrm{m}$, Geophys. Res. Lett., 23, 3195-3198, https://doi.org/10.1029/96GL02921, 1996.

Randall, C. E., Bevilacqua, R. M., Lumpe, J. D., and Hoppel, K. W.: Validation of POAM III aerosols: Comparison to SAGE II and HALOE, J. Geophys. Res.-Atmos., 106, 27525-27536, https://doi.org/10.1029/2001JD000528, 2001.

Randel, W. J., Park, M., Emmons, L., Kinnison, D., Bernath, P., Walker, K. A., Boone, C., and Pumphrey, H.: Asian Monsoon Transport of Pollution to the Stratosphere, Science, 328, 611613, https://doi.org/10.1126/science.1182274, 2010.

Rieger, L. A., Bourassa, A. E., and Degenstein, D. A.: Stratospheric aerosol particle size information in Odin-OSIRIS limb scatter spectra, Atmos. Meas. Tech., 7, 507-522, https://doi.org/10.5194/amt-7-507-2014, 2014.

Rieger, L. A., Malinina, E. P., Rozanov, A. V., Burrows, J. P., Bourassa, A. E., and Degenstein, D. A.: A study of the approaches used to retrieve aerosol extinction, as applied to limb observations made by OSIRIS and SCIAMACHY, Atmos. Meas. Tech., 11, 3433-3445, https://doi.org/10.5194/amt11-3433-2018, 2018.

Rieger, L. A., Zawada, D. J., Bourassa, A. E., and Degenstein, D. A.: A Multiwavelength Retrieval Approach for Improved OSIRIS Aerosol Extinction Retrievals, J. Geophys. Res.-Atmos., 124, 7286-7307, https://doi.org/10.1029/2018JD029897, 2019.

Rozanov, V. V., Rozanov, A. V., Kokhanovsky, A. A., and Burrows, J. P.: Radiative transfer through terrestrial atmosphere and ocean: Software package SCIATRAN, J. Quant. Spectrosc. Ra., 133, 13-71, https://doi.org/10.1016/j.jqsrt.2013.07.004, 2013.

Russell III, J. M., Gordley, L. L., Park, J. H., Drayson, S. R., Hesketh, W. D., Cicerone, R. J., Tuck, A. F., Frederick, J. E., Harries, J. E., and Crutzen, P. J.: The Halogen Occultation Experiment, J. Geophys. Res., 98, 10777-10797, 1993.
Russell, P. B. and McCormick, M. P.: SAGE II Aerosol Data Validation and Initial Data Use: An Introduction and Overview, J. Geophys. Res., 94, 8335-8338, 1989.

Sioris, C. E., Boone, C. D., Bernath, P. F., Zou, J., McElroy, C. T., and McLinden, C. A.: Atmospheric Chemistry Experiment (ACE) observations of aerosol in the upper troposphere and lower stratosphere from the Kasatochi volcanic eruption, J. Geophys. Res.-Atmos., 115, D00L14, https://doi.org/10.1029/2009JD013469, 2010.

Thomason, L. W. and Taha, G.: SAGE III aerosol extinction measurements: Initial results, Geophys. Res. Lett., 30, 1631, https://doi.org/10.1029/2003GL017317, 2003.

Thomason, L. W., Pitts, M. C., and Winker, D. M.: CALIPSO observations of stratospheric aerosols: a preliminary assessment, Atmos. Chem. Phys., 7, 5283-5290, https://doi.org/10.5194/acp-75283-2007, 2007.

Thomason, L. W., Burton, S. P., Luo, B.-P., and Peter, T.: SAGE II measurements of stratospheric aerosol properties at non-volcanic levels, Atmos. Chem. Phys., 8, 983-995, https://doi.org/10.5194/acp-8-983-2008, 2008.

Vernier, J.-P., Thomason, L. W., and Kar, J.: CALIPSO detection of an Asian tropopause aerosol layer, Geophys. Res. Lett., 38, L07804, https://doi.org/10.1029/2010GL046614, 2011.

von Savigny, C., Ernst, F., Rozanov, A., Hommel, R., Eichmann, K.U., Rozanov, V., Burrows, J. P., and Thomason, L. W.: Improved stratospheric aerosol extinction profiles from SCIAMACHY: validation and sample results, Atmos. Meas. Tech., 8, 5223-5235, https://doi.org/10.5194/amt-8-5223-2015, 2015.

Winker, D. M., Hunt, W. H., and McGill, M. J.: Initial performance assessment of CALIOP, Geophys. Res. Lett., 34, L19803, https://doi.org/10.1029/2007GL030135, 2007. 